\title{
A taxonomic overview and key to the ants of Barrow Island, Western Australia
}

\author{
B. E. Heterick
}

Department of Environment and Agriculture, Curtin University, Bentley, Western Australia 6102, Australia. Email: B.Heterick@Curtin.edu.au

\begin{abstract}
This work characterises the ant (Hymenoptera: Formicidae) fauna of Barrow Island, Western Australia, and provides a key to the workers and several unique reproductives of the 117 species recorded from the island thus far. In all, 11 of the 13 subfamilies of Western Australian ants have been recorded from Barrow Island, but Myrmeciinae and Heteroponerinae are absent. At a generic level, the fauna of the island is less rich, holding 36 of the 71 genera currently known from Western Australia. The ant fauna is characteristic of the Eremaean Botanical Province of the Pilbara, rather than that of the Carnarvon Basin from which Barrow Island is geologically derived. Ninety-three ant species (79.5\% of the total on Barrow Island) are shared with the ant fauna of the Pilbara region on the adjoining mainland, but only 52 species (44.4\% of the total) are shared with the ant fauna of the Carnarvon Basin. The island is very rich in unspecialised and thermophilic ant species. Five such genera, i.e., Iridomyrmex (14 spp.), Monomorium (13 spp.), Polyrhachis (12 spp.), Melophorus (10 spp.), and Camponotus (nine spp.) make up almost 50\% (i.e., 49.6\%) of the island's ant fauna. Very few ants appear to be endemic to Barrow Island. The relative proportions of the two major subfamilies (Formicinae and Myrmicinae, together comprising 61.5\% of the total ant richness) are similar to the proportions found in the South-west Botanical Division for these two subfamilies (i.e., 65.9\%), with Barrow Island having a slightly lower ratio of formicines to myrmicines than is found in the south-west of the state. An estimate of the total number of ant species likely to occur on Barrow Island, using the Estimate-S program (Colwell 2009), suggests that a maximum of fourteen additional species may be as yet unrecorded.
\end{abstract}

KEYWORDS: Barrow Island, ant fauna, taxonomic key, Chevron Australia

\section{INTRODUCTION}

Barrow Island is a $202 \mathrm{~km}^{2}$ island located some $50 \mathrm{~km}$ off the north-west Australian coast, with the ports of Onslow and Dampier being the nearest major population centres on the adjoining Australian mainland. The climate on the island is warm to hot, with the highest maxima occurring in January and February $\left(33.2^{\circ} \mathrm{C}\right.$ and $33.3^{\circ} \mathrm{C}$, respectively) and the lowest minima in July and August $\left(17.7^{\circ} \mathrm{C}\right.$ and $17.8^{\circ} \mathrm{C}$, respectively). Overall, the average annual maximum is $29.1^{\circ} \mathrm{C}$ and the average annual minimum is $22.2^{\circ} \mathrm{C}$. The mean annual rainfall is $324.6 \mathrm{~mm}$, most of it falling in the period January to May (Bureau of Meteorology). This is the period during which cyclones or monsoonal lows affect Australia's northern half. In appearance the island is rather uniform with flat spinifex grasslands dominating, interspersed with termite mounds. However, more than 227 other plants can be found on the island (Australian Broadcasting Corporation 2011), many of them arid-adapted. Fauna includes 15 terrestrial and seven marine mammals (Bamford and Bamford 2005).

Barrow Island has been subject to a baseline survey since 2005 (Callan et al. 2011) by Curtin University students and by employees associated with the Gorgon natural gas project (Chevron Australia). Among the more than 2000 terrestrial invertebrate species collected since 2005 have been 117 species of ants. Accurately documenting the taxonomy of the ants collected on Barrow Island has been a slow and painstaking process. This is partially due to our still incomplete knowledge of the West Australian ant fauna, and partially due to the isolation of Perth from the main centres of myrmecological expertise and the major ant collections on the Eastern Australian seaboard. A short summary of the history of Western Australian ant taxonomy is in order: the ants of Western Australia have been described in a mainly piecemeal fashion for a century-and-a-half, with most early taxonomic publications resulting from collections made by foreign researchers who came to Western Australia on expeditions, e.g., W. Michaelsen and R. Hartmeyer's expedition to South-western Australia, E. Mjöberg's 1910-1911 expedition to North-western Australia (the ants were described by Forel in 1907 and 1915, respectively) and W. M. Wheeler, who 
visited Rottnest Island in 1931 (Wheeler 1934). Other significant taxonomic contributions made by overseas researchers include those of F. Smith (1858, 1877); C. Emery (e.g., 1895, 1898) and W. C. Crawley (1915, 1922). Important early Australian researchers of Western Australian Formicidae did not appear until the 1920's and were led by J. Clark (a number of papers, most notably, 1924a, 1924b, 1926, 1930, 1934, 1936, 1938, 1943 and 1951) and Father J. J. McAreavey (1947, 1949, 1956 and 1957). In the post WWII period, R. W. Taylor described several uncommon Western Australian ants and assisted in the revision of the Australian bulldog ants (Taylor 1962, Taylor 1973, Ogata and Taylor 1991), while more mainstream taxa have been treated in revisionary works by Shattuck and his colleagues (e.g., Shattuck 1993a; Shattuck 1993b; Shattuck 1996; Shattuck and McMillan 1998; Shattuck and McArthur 2002; Shattuck 2007; Shattuck 2008; Shattuck 2009) and Heterick (Heterick 2001; Heterick 2003; Heterick and Shattuck 2011). Heterick has also produced a handbook on the ants of South-western Australia, with several nomenclatural amendments but no new species descriptions (Heterick 2009). Despite these efforts, however, the Western Australian ant fauna is still relatively poorly known compared with that of the eastern Australian states. A name cannot confidently be assigned to about $38 \%$ of the morphospecies of the comprehensive Western Australian holdings in the Curtin Ant Collection, and to more than $46 \%$ of the taxa whose range lies outside of the Southwestern Botanical Division (i.e., around 133 spp.).

\section{CHARACTERISTICS OFTHE BARROW ISLAND ANT FAUNA}

76 of the 117 species of Barrow Island ants can be assigned a name, this constituting $65.0 \%$ of the ant fauna of the island. The taxa themselves are very representative of the broader Eremaean ant fauna, with 93 species shared between Barrow Island and the adjoining mainland. This represents $79.5 \%$ of the ants recognised from Barrow Island and 38.0\% of the 245 Pilbara ants identified in Heterick et al. (2010). By way of contrast, only 52 ant species from Barrow Island (i.e., $44.4 \%$ of the total recognized) are included within the 243 species of ants identified by Gunawardene and Majer (2004) from the southern Carnarvon Basin, the latter reflecting a much more temperate fauna. This is an interesting observation in view of the fact that Barrow Island was part of the Carnarvon Basin until 8000 years ago, when it was separated by rising sea levels (Eldridge et al. 1999). Five of the ants collected from Barrow Island are definitely not represented elsewhere in the Curtin Ant Collection and, of these, four are almost certainly unnamed (i.e., Rhytidoponera ?micans complex sp. JDM 1129, Discothyrea sp. JDM 1130 (a queen), Carebara sp. JDM 1131 and Meranoplus sp. JDM 1133), while Probolomyrmex latalongus Shattuck et al. (2012) (a queen) also occurs elsewhere in the north of the Australian mainland. Four Barrow Island ant species, including the two mentioned above, have only been collected as queens or males.

At the subfamily level, the fauna is taxonomically rich, with 11 subfamilies represented out of the 22 extant subfamilies currently recognized (Ward, 2007; Rabeling et al., 2008). At the generic level the fauna is less diverse, reflecting the harsh, largely waterless landscape. Only 36 of the 71 genera currently known from Western Australia occur on Barrow Island. Large, important mainland groups absent from Barrow Island or represented by only one species include Myrmecia (absent), Plagiolepis (absent), Prolasius (absent) Stigmacros (one species) and all of the Dacetini, apart from one Strumigenys species. No Myrmeciinae or Heteroponerinae are found on Barrow Island. On the other hand, genera with many unspecialized or thermophilic species are wellrepresented, e.g., Iridomyrmex (14 spp.), Monomorium (13 spp.), Polyrhachis (12 spp.), Melophorus (10 spp.), and Camponotus (nine spp.). Together, these five genera make up almost $50 \%$ (i.e., $49.6 \%$ ) of the Island's ant fauna.

An interesting feature of the Barrow Island ants is the relative proportions of the two major subfamilies, Formicinae and Myrmicinae. Formicinae comprise $38.9 \%$ of the morphospecies of ants from the Southwest Botanical Province held in the Curtin Ant Collection, and Myrmicinae comprise 27.0\%. This disparity is rather less pronounced on Barrow Island, with Formicinae accounting for 31.6\% of the morphospecies compared with $29.9 \%$ for the Myrmicinae. On Barrow Island, a few large genera in these two groups are the most significant contributors; for the Formicinae, Polyrhachis, Camponotus and Melophorus comprise $83.8 \%$ of the formicine morphospecies, and Monomorium, Meranoplus (six spp.), Pheidole (five spp.) and Tetramorium (three spp.) comprise $77.1 \%$ of the myrmicines (Table 1).

Since invertebrate sampling has taken place on Barrow Island annually since 2005, there are sufficient data for the Island's total ant richness to be assessed. This was done using the EstimateS program, version 8.2 (Colwell 2009) with four different estimators selected. All four species accumulation curves show a strong flattening with added sampling. The sampling based rarefaction curve (Mao Tau), examining a sub-sample of the pooled total species richness, produced the most conservative estimate of 111 species, which actually slightly understates the present record of 117 morphospecies. Total richness estimators (Chao 1 and Jack 1) predicted 131 and 127 (126.5) species, respectively. Bootstrapping resulted in an intermediate estimate of 118 species (118.3). These results suggest that the ant fauna of Barrow Island, although comprehensively sampled, may yet yield up to 14 taxa that are currently unrecognised. 


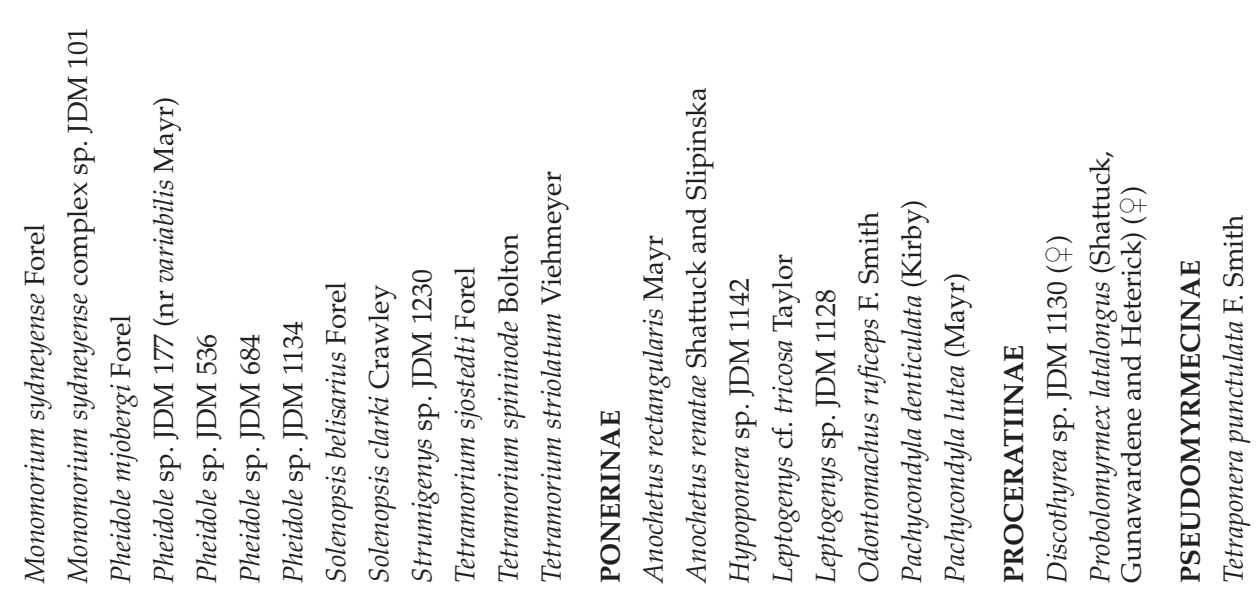

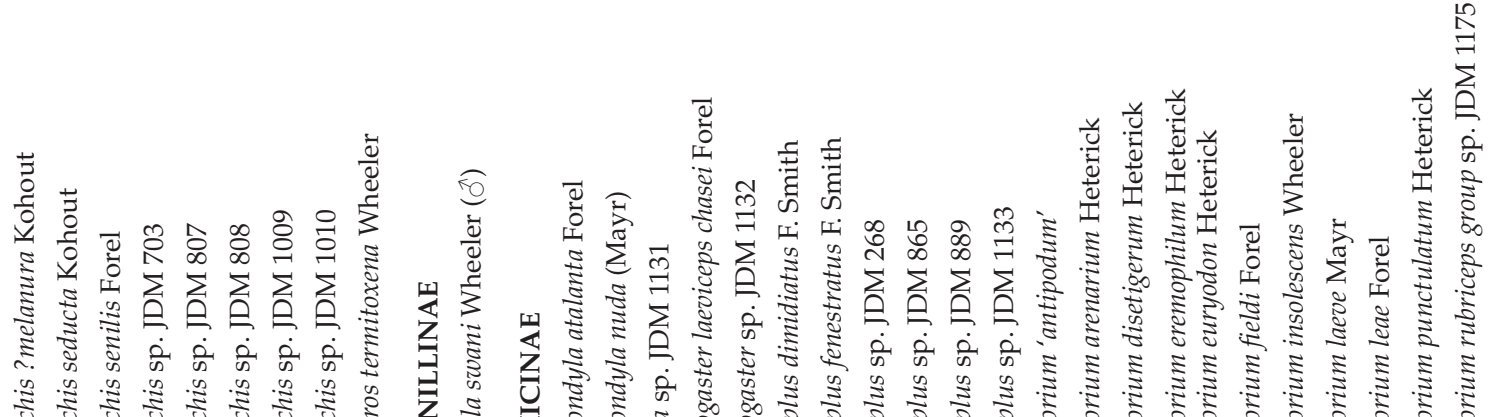

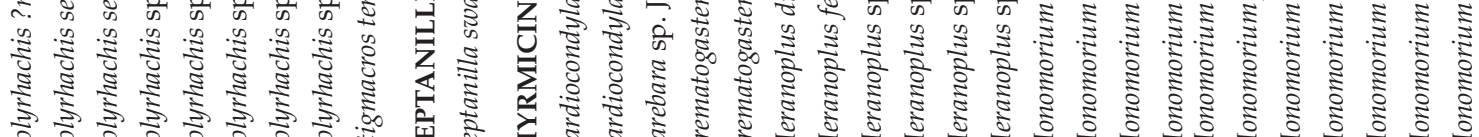

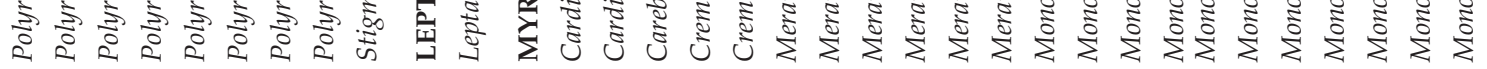

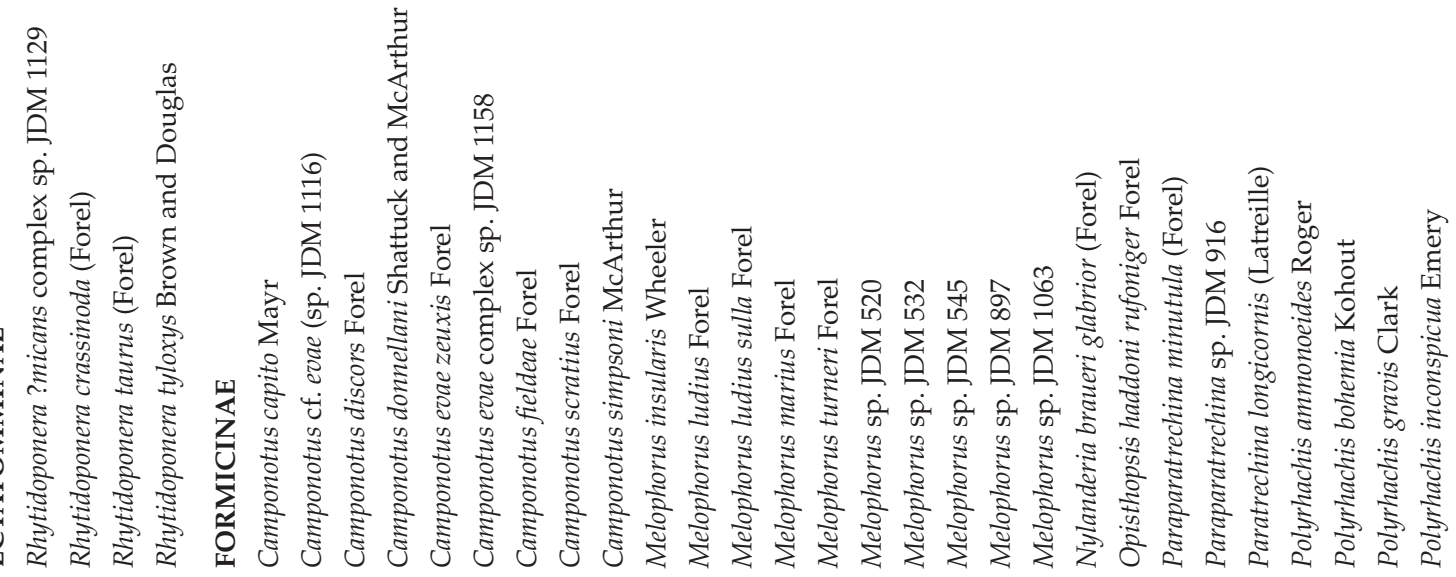

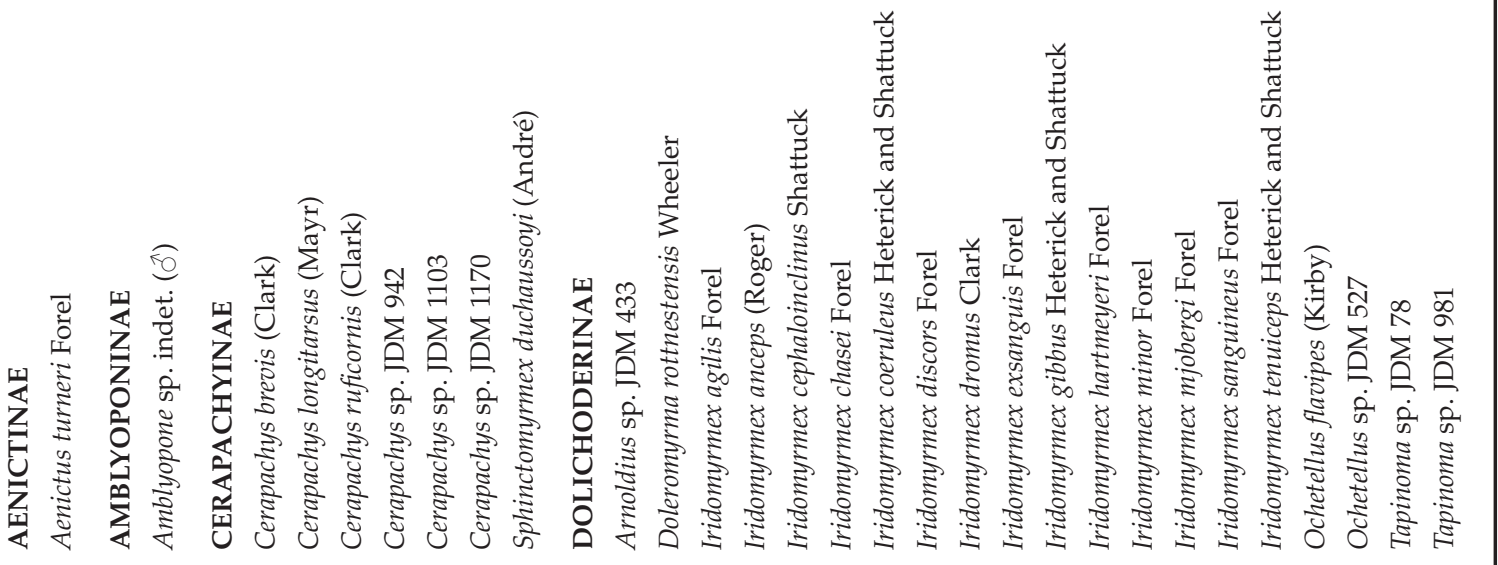




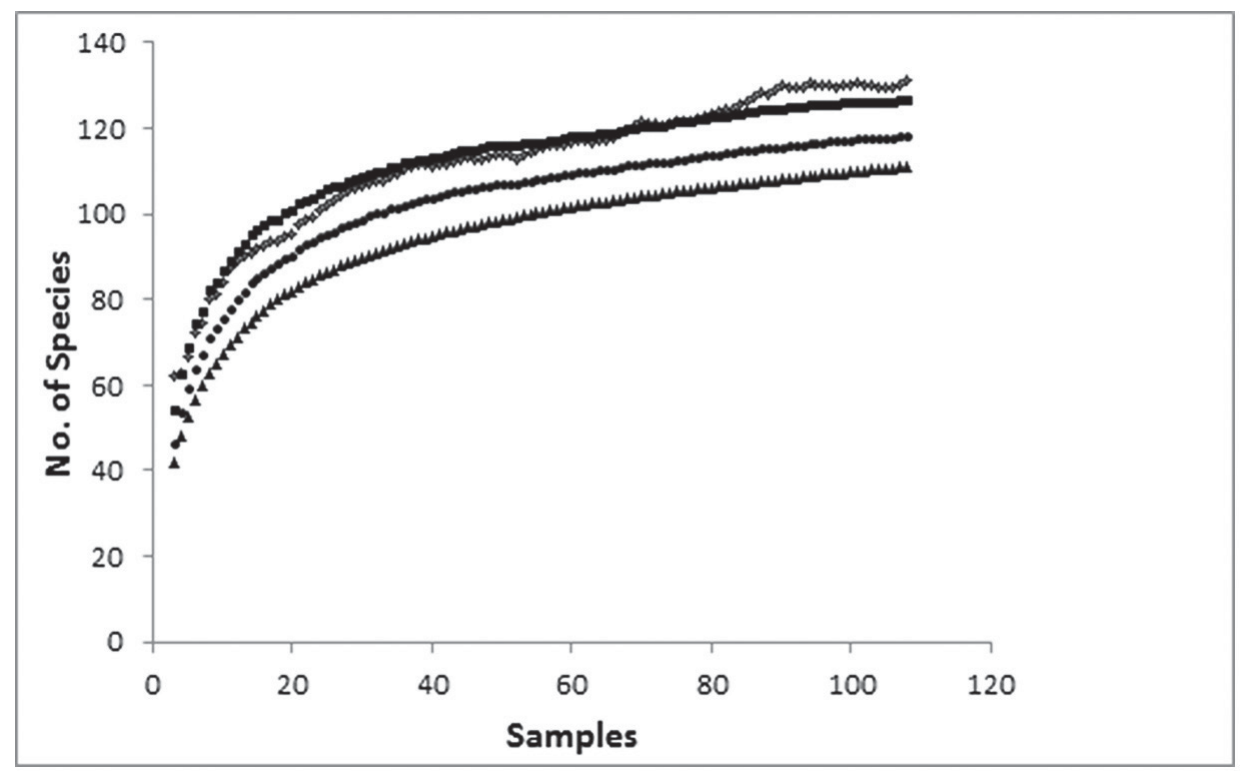

FIGURE $1 \quad$ Presence/absence species accumulation curve illustrating estimated number of ant species on Barrow Island based on four estimators (Mao Tau (ی), Chao 1 Mean $(\bullet)$ Jackknife 1 Mean $(\mathbf{\bullet})$ and Bootstrap Mean (•)) in EstimateS version 8.2 (Colwell 2009).

\section{KEY TO THE ANTS OF BARROW ISLAND}

For technical terms used in the key below, the reader is referred to Heterick (2009, pp. 10-11, and also pp. 198-201 (glossary)).

$(\mathrm{Nb}$. This key recognises mainly workers, but the two queens mentioned above are also included as they are the only representatives of their respective genera. Amblyoponinae, represented by one unidentified male, is also included. Numbers in the case of unnamed species refer to vouchers used in the Curtin University Ant Collection.)

1. Dorsum of pygidium flattened, margins of flattened area armed laterally, posteriorly, or both, with a series of denticles or short spines (Figure 2); abdominal segments $\mathrm{V}$ VII with spiracles visible in intact specimen; promesonotal suture usually completely absent (absent in all known Australian species)

(Cerapachyinae). . .1

Dorsum of pygidium without series of denticles or short spines; abdominal segments V-VII with spiracles visible only when abdomen is distended or dissected (except for Aenictinae); promesonotal suture present or absent.
2. Abdominal segments III-VII with distinct constrictions between divisions so as to present an uneven outline (Figure 3) (Sphinctomyrmex)

Sphinctomyrmex duchaussoyi André

Abdominal segments III-VII with divisions smoothly joined, so that the outline is even (Figure 4) (Cerapachys) .. 3

3. Dorsal surface of mesosoma rounded onto lateral surfaces, lateral carinae absent or vestigial (Figure 5)

Cerapachys longitarsus (Mayr)

Dorsal surface of mesosoma delimited from lateral surfaces by distinct carinae (Figure 6)

4. Body concolorous red ............................................ 5

Body black or bicoloured ...................................... 6

5. Ocelli present; posterior corners of head with weakly defined to strong but incomplete dorsolateral carina curving towards eye (Figure 7) .....................Cerapachys sp. JDM 1103

Ocelli absent; posterior corners of head without dorsolateral carina curving towards eye (Figure 8) .............. Cerapachys sp. JDM 1170 
6. Petiole distinctly lighter coloured (yellow to light brown) than mesosoma and post-petiole Cerapachys brevis (Clark)

Petiole black, the same colour as the mesosoma and postpetiole.... .7

7. Petiolar node a posteriorly rounded square in dorsal view with its posterior margin rimmed by a narrow membrane; gaster bright orange contrasting with black postpetiole (Figure 9) Cerapachys sp. JDM 942

Petiolar node rectangular, without a narrow membrane, its posterior angles denoted by small denticles; gaster uniformly black, the same as the postpetiole (Figure 10)

Cerapachys ruficornis (Clark)
8. Waist consisting of a single distinct segment (the petiole); abdomen may be more-or-less deeply impressed behind segment III (Figure 11)

Waist consisting of two distinct segments (the petiole and the postpetiole), segment III being distinctly separate from remaining abdominal segments, which are smoothly rounded (Figure 12).

9. Apex of hypopygium with a circular or semi-circular cone (the acidopore), usually projecting as a nozzle and modified to spray formic acid and often fringed with setae (Formicinae) (Figures 13, 14)..... 10

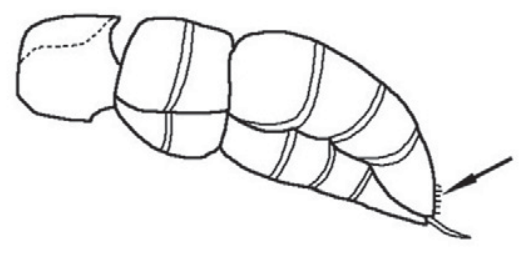

FIGURE 2

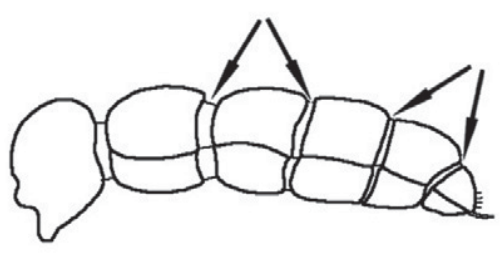

FIGURE 3

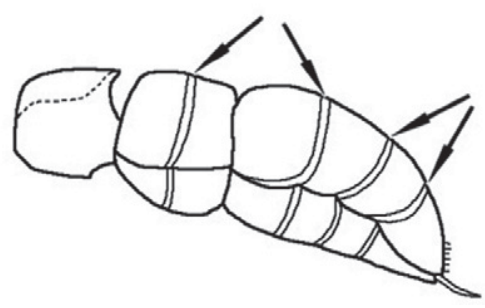

FIGURE 4

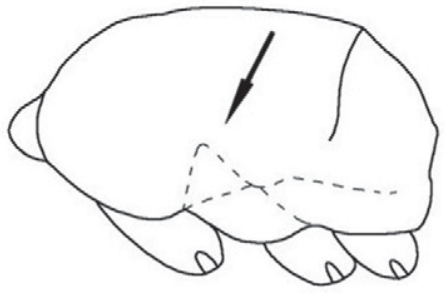

FIGURE 5

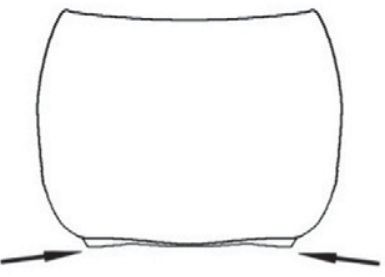

FIGURE 9

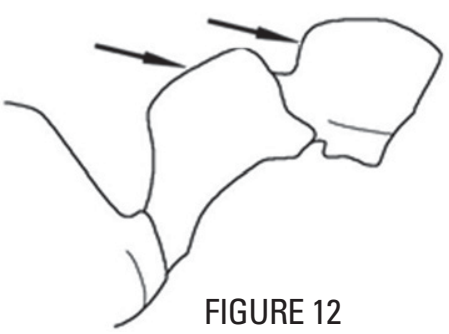

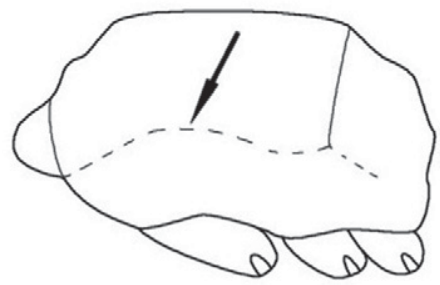

FIGURE 6

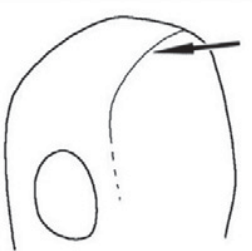

FIGURE 7

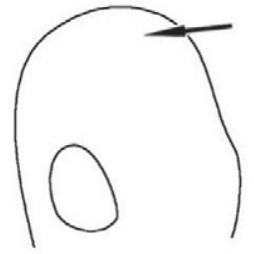

FIGURE 8

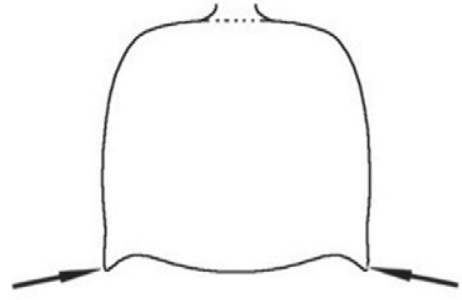

FIGURE 10

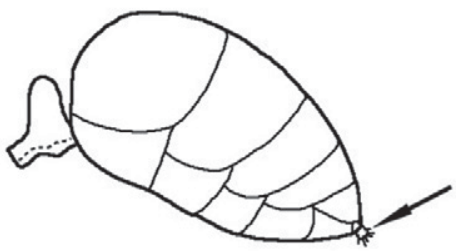

FIGURE 13

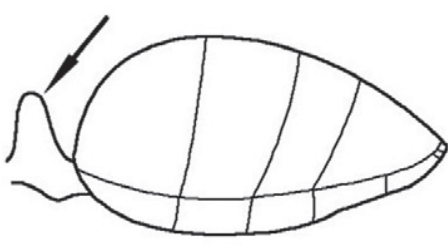

FIGURE 11

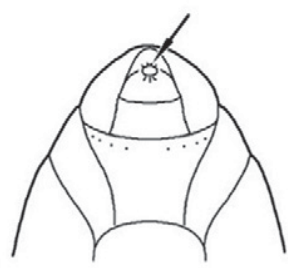

FIGURE 14 
Apex of hypopygium lacking an acidopore, either terminating in a sting (modified ovipositor) or with a narrow, laterally oriented slit that is situated ventrally (e.g., Figure 15)

10. Antenna with 11 segments (including the scape) (Stigmacros)

Stigmacros termitoxena Wheeler

Antenna with 12 segments (including the scape) (other formicine genera). .. 11

11. Lower corner of mesosoma below propodeum without an opening (to the metapleural gland) fringed with long setae, though a few scattered setae may be present (Figure 16) ......

Lower corner of mesosoma below propodeum with an opening (just above hind coxa) that is often fringed with long setae (Figure 17)..... 32

12. Upper plate of first gastral segment (first tergite) approximately half the total length of gaster; spines or sharp angles present on propodeum and petiolar node in Western Australian species (Figure 18); one worker caste (Polyrhachis)......

Tergite of first gastral segment much less than half total length of gaster, spines always absent on body segments in Western Australian species; propodeal angle (if present) rounded (Figure 19); major and minor worker castes, at least, always present; media workers often present (Camponotus).. 24

13. Node squamiform to semi-cuboidal and directed posteriad, never with flattened dorsal plateau and usually armed with four denticles or short spines, rarely with two short, erect parallel spines but never with two elongate, recurved spines; propodeum either unarmed or armed with short, upturned flanges, denticles or short, flattened spines (Figure 20) (subgenus Campomyrma) 14

Node never squamiform, in Barrow Island species its dorsum always produced in the form of two elongate, recurved spines; propodeal angles armed with two long, acute spines (Figure 21) .

14. Mesosoma, gaster and legs with many short, bristly, erect setae.

Polyrhachis gravis Clark

Mesosoma, gaster and legs glabrous .15
15. Dorsum of node armed with two short but distinct spines that are round in cross-section; in profile, head lacking a sharp to blunt carina between the eye and the vertex (Figure 22) Polyrhachis sp. JDM 703

Dorsum of node either unarmed or armed with two much abbreviated, flattened denticles; head with sharp to blunt carina between the eye and the vertex (Figure 23) 16

16. In dorsal view, propodeum strongly attenuated and trapezoidal in appearance, its posterior margin $\approx 0.5 \mathrm{x}$ its anterior margin (i.e., the metanotal groove); propodeum finely microreticulate-striate (Figure 24).

Polyrhachis sp. JDM 1009

In dorsal view, propodeum weakly attenuated and rectangular in appearance, its posterior margin $\geq 0.65 x$ its anterior margin; propodeum more noticeably striate (Figure 25)

17. In rear view, propodeal dorsum separated from propodeal declivity by a distinct carina; smaller species ( $\mathrm{HW} \leq 1.4 \mathrm{~mm}$ ) (Figure 26) Polyrhachis inconspicua Emery

In rear view, propodeal dorsum not separated from propodeal declivity by a distinct carina, although there may be a bluntly defined angle; larger species ( $\mathrm{HW} \geq 1.7 \mathrm{~mm}$ ) (Figure 27)......... .Polyrhachis sp. JDM 1010

18. In dorsal view, pronotum as long as or longer than mesonotum and propodeal dorsum combined; humeral angles dentate (Figure 28) (subgenus Chariomyrma). 19

In dorsal view, pronotum much shorter than mesonotum and propodeal dorsum combined; humeral angles rounded, not armed in WA species (Figure 29) (subgenus Hagiomyrma) 21

19. Lateral margins of mesonotum and propodeum with spinous processes (Figure 30) Polyrhachis sp. JDM 808

Lateral margins of mesonotum and propodeum entire (Figure 31).

20. In dorsal view, sculpture of dorsum of mesosoma easily visible and lacking obscuring pubescence

Polyrhachis senilis Forel 


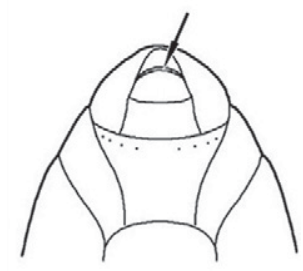

FIGURE 15

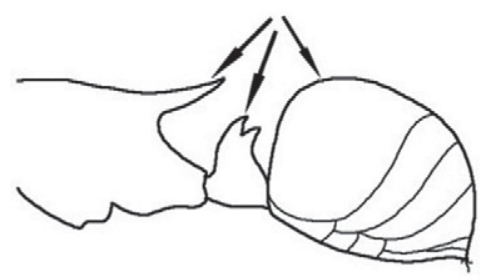

FIGURE 18

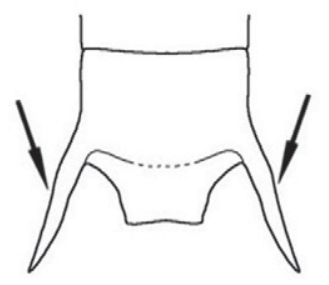

FIGURE 21

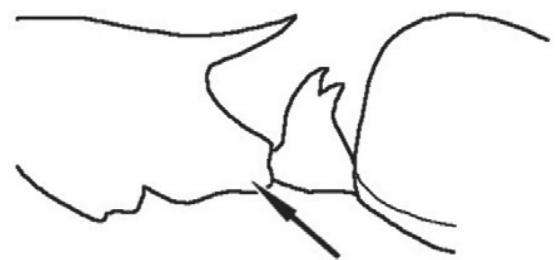

FIGURE 16

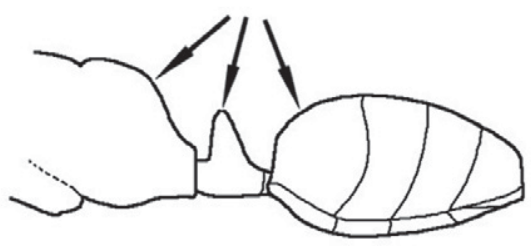

FIGURE 19

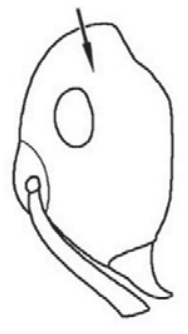

FIGURE 22

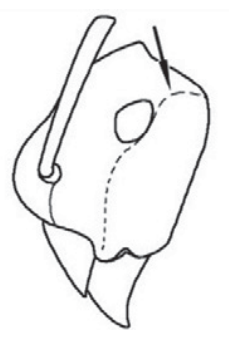

FIGURE 23

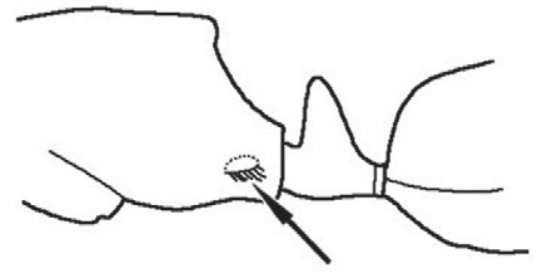

FIGURE 17

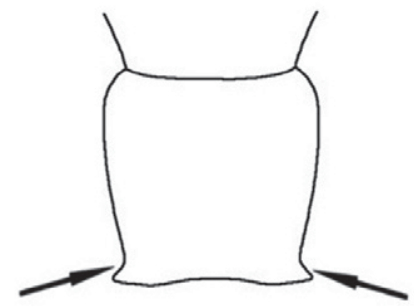

FIGURE 20

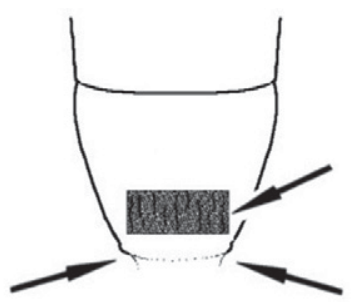

FIGURE 24

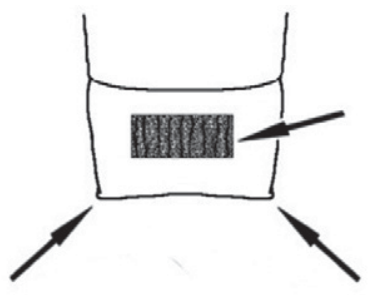

FIGURE 25

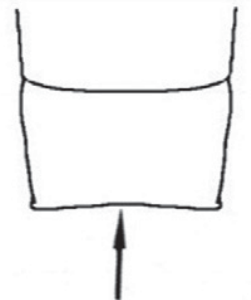

FIGURE 26

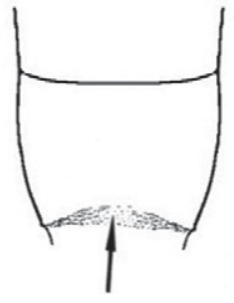

FIGURE 27

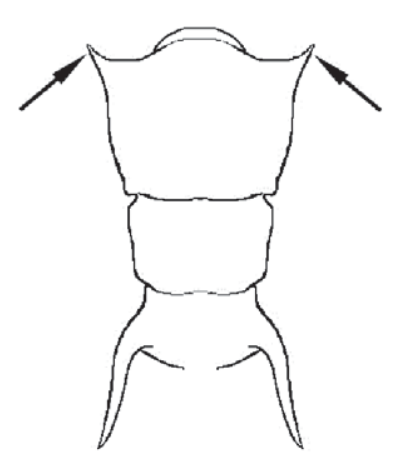

FIGURE 28

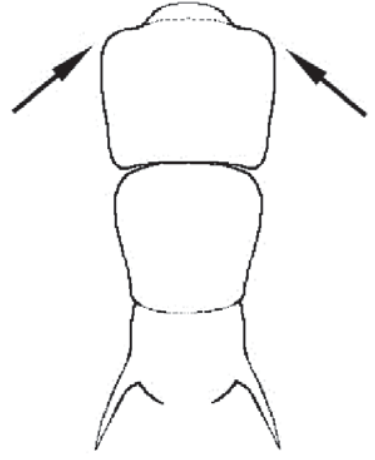

FIGURE 29

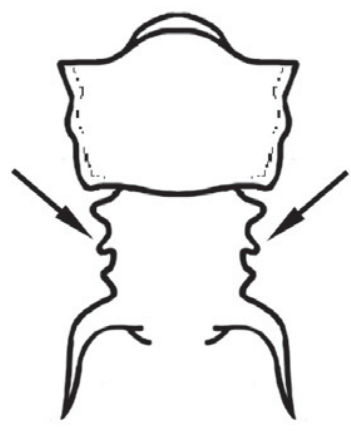

FIGURE 30

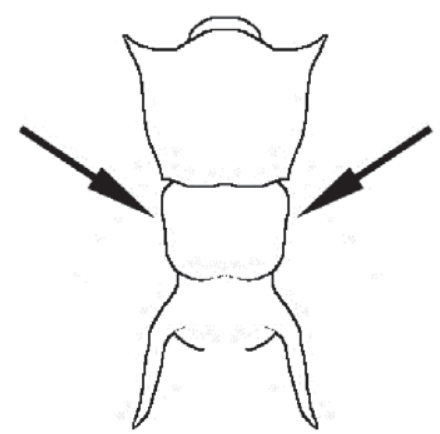

FIGURE 31 
In dorsal view, sculpture of dorsum of mesosoma partially obscured by golden pubescence.................. Polyrhachis sp. JDM 807

21. Foreparts brick-red, gaster chocolate .Polyrhachis bohemia Kohout

Ground colour of entire body blackish........ 22

22. Extremities of the petiolar spines hooked and projected ventrad (Figure 32) Polyrhachis ammonoeides Roger

Extremities of the petiolar spines recurved but not hooked and projected ventrad (Figure 33)

23. In dorsal view, sculpture of mesosoma very finely and evenly microreticulate; antennal scape with erect bristles

Polyrhachis seducta Kohout

In dorsal view, sculpture of mesosoma finely longitudinally striate, the striae joined by irregular cross ribs; antennal scape lacking erect bristles

Polyrhachis ?melanura Kohout

24. Mentum of major and minor worker with elongate, J-shaped setae near its posterior margin (Figure 34) .

Camponotus donnellani Shattuck and McArthur

Without elongate, J-shaped setae on posterior margin of mentum (Figure 35)

25. Major and minor workers with five mandibular teeth; black or very dark brown ants with a high, truncate mesosoma and a steeply declivitous propodeal declivity........ 26

Major and minor workers with maximum of six or more teeth; if dentition ambiguous due to abrasion of small denticles, and with high mesosoma (a few C. scratius minor workers), then paler in colour

26. Body and legs notably bristly, the erect setae on the legs raised at an angle of $\approx 45^{\circ}$ in both major and minor workers (Figure 36). Camponotus cf. evae (sp. JDM 1116)

Body and legs less hairy, the erect setae on the legs appressed or raised at an angle of $\approx 15^{\circ}$ or less (Figure 37)..... 27

27. A few erect setae visible on the venter of the head capsule in major and minor workers ...... . Camponotus evae zeuxis Forel

Erect setae completely lacking on the venter of the head capsule in major and minor workers
28. In full-face view, head of major worker with straight sides (Figure 38); first gastral plate (tergite) of minor worker with one welldefined row of non-marginal erect setae ......... . Camponotus evae complex sp. JDM 1158

In full-face view, head of major worker, with convex sides (Figure 39); first gastral plate (tergite) of minor worker with several poorly defined rows of non-marginal erect setae........ Camponotus simpsoni McArthur

29. In full-face view, anterior median portion of clypeus of both major and minor worker produced as a squared-off projection with the corners at an angle of $90^{\circ}$ to the lateral sectors of the clypeus (Figure 40)

Camponotus fieldeae Forel

In full-face view, anterior median portion of clypeus not so produced, and usually projecting as a weak convexity, the anterior median angles (if present) oblique (Figure 41)

30. In profile, mesonotum and propodeum of major and minor workers elongate and undulant, saddle-shaped in the minor worker (Figure 42) ...................Camponotus capito Mayr

In profile, mesonotum and propodeum high in major and minor worker, gradually curving into a steep propodeal declivity (Figure 43) 31

31. Species larger ( $\mathrm{HW}$ major worker $\geq 2.5 \mathrm{~mm}$, $\mathrm{HW}$ minor worker $\geq 0.9 \mathrm{~mm}$ ); paired, erect pronotal setae in minor worker placed in centre of pronotum (Figure 44)

Camponotus discors Forel

Species smaller (HW major worker $\leq 1.4 \mathrm{~mm}$, $\mathrm{HW}$ minor worker $\leq 0.6 \mathrm{~mm})$; paired, erect pronotal setae in minor worker placed near to promesonotal suture (Figure 45).

Camponotus scratius Forel

32. Eyes very large and placed on posterior angles of head capsule (Figure 46) .... . Opisthopsis haddoni rufoniger Forel

Eyes of moderate size and placed at sides or front of head capsule, but not on posterior angles (Figure 47).

33. Propodeal spiracle slit or comma-like (Figure 48); clypeus and underside of head usually with profuse, long, curved setae (Figure 49); polymorphic with major, media and minor workers present (Melophorus) .34 


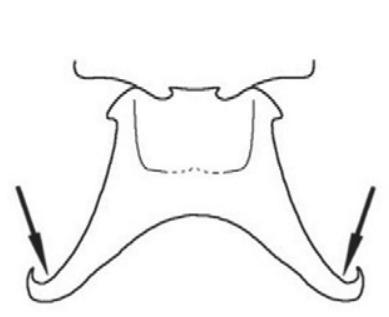

FIGURE 32

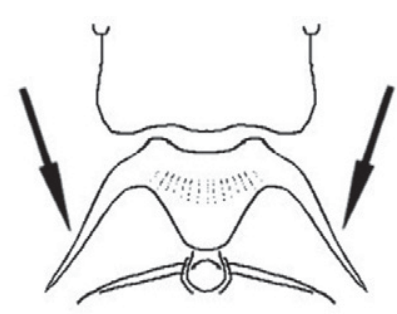

FIGURE 33

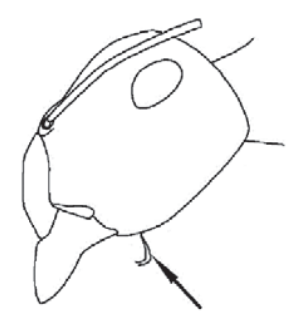

FIGURE 34

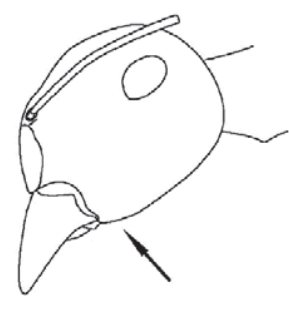

FIGURE 35

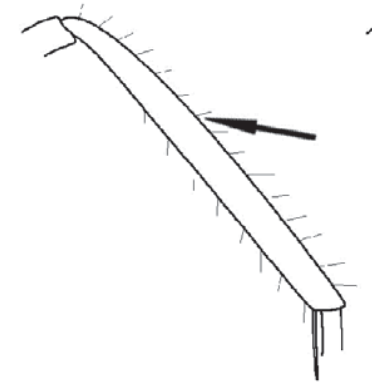

FIGURE 36

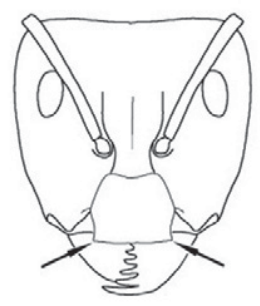

FIGURE 40

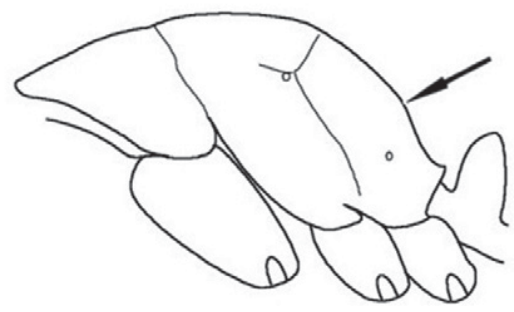

FIGURE 43

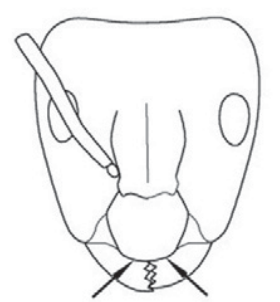

FIGURE 41

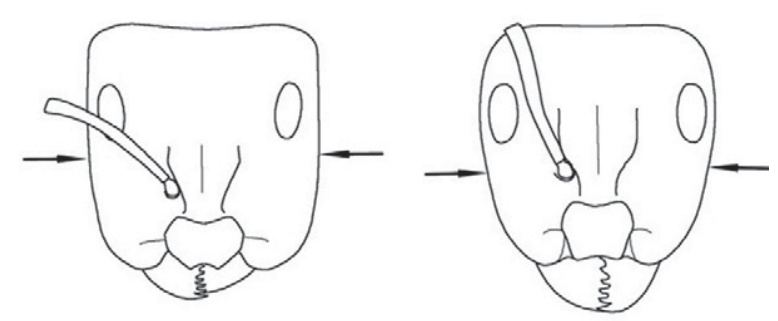

FIGURE 38
FIGURE 39

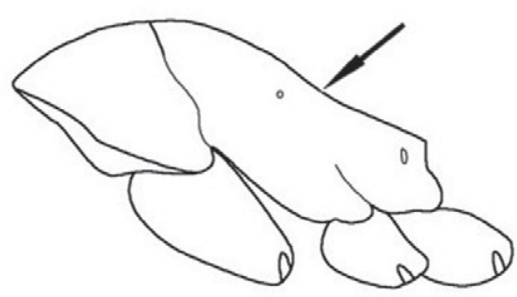

FIGURE 42

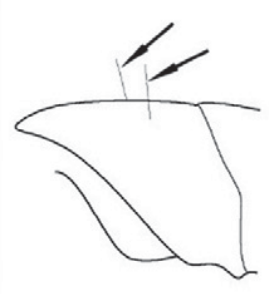

FIGURE 44

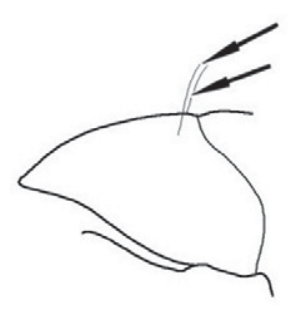

FIGURE 45

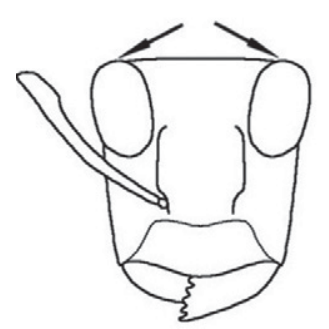

FIGURE 46

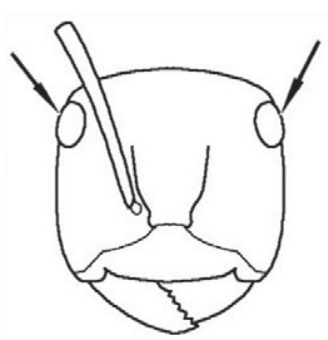

FIGURE 47

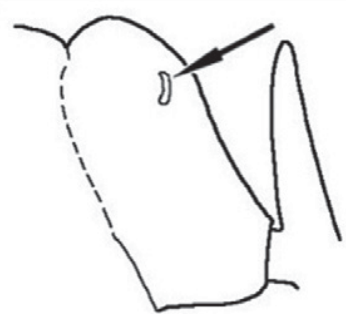

FIGURE 48

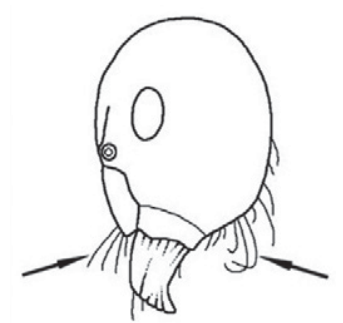

FIGURE 49 
Propodeal spiracle oval or round (Figures 50); clypeus and underside of head and mandibles with few or no long, curved setae (Figure 51); monomorphic species.. .43

34. In full-face view, anterior clypeal margin in all worker castes convex, apron-like and covering whole or part of the retracted mandible, the medial clypeal sector often produced so that it is protrusive when seen in profile; clypeal psammophore frequently with coarse and well-separated ammochaetae, these always placed on or just above anterior margin (Figure 52); in profile, propodeum elongate and oblique or broadly rounded (Figure 53) 35

In full-face view, anterior clypeal margin in all worker castes variable, but not covering whole or part of the retracted mandible, the medial clypeal sector not narrowly protrusive, although it may be broadly protuberant; clypeal psammophore often placed along the midpoint of the clypeus or even above it (Figure 54); in profile, propodeum typically truncate or narrowly rounded (Figure 55)

35. Mesonotum and propodeum of minor worker confluent, metanotal groove completely lacking (major worker unknown) (Figure 56) ..Melophorus sp. JDM 897

Mesonotum and propodeum of minor worker not confluent; metanotal groove usually well-developed, but if not then a furrow that represents the metanotal groove is present (Figure 57). 36

36. In profile, mesosoma of minor worker with a compact appearance, its dorsal outline describing a pronounced arc due to shape of the mesonotum and mesopleuron (mesosternal outline and dorsum of mesonotum strongly convergent anteriorly) (Figure 58); in profile, clypeus of all workers gently recurved and produced as a small ledge over basal sector of mandibles (Figure 59) .Melophorus insularis Wheeler

In profile, mesosoma of minor worker with elongate gracile appearance, its dorsal outline straight or describing a weak arc (mesosternal outline and dorsum of mesonotum weakly convergent to subparallel anteriorly (Figure 60)); in profile, clypeus of all workers produced as a flange that projects anteriad well past basal sector of mandibles (Figure 61) Melophorus sp. JDM 545
37. Mesosoma with metanotum apparently developed and confluent with mesonotum, often extending over the propodeum; metanotal groove obsolete, its position indicated only by a superficial, transverse furrow; propodeum reduced in size and wedge-shaped, with narrow end of wedge often under fold of metanotum; metathoracic spiracle lateral and situated within metanotal sector (Figure 62)

Melophorus sp. JDM 1063

Worker mesosoma of normal appearance, with metathoracic spiracle situated on or near dorsum of mesosoma (Figure 63) .38

38. Gaster with curved erect, semi-erect setae and a few decumbent setae only, genuine appressed setae lacking; body strongly sculptured and hirsute, antennal scapes and legs with whorls of many fine, straight setae Melophorus sp. JDM 532

If legs and antennal scapes with whorls of setae, then gaster with at least well-spaced appressed setae between the longer, erect or semi-erect pilosity.....

39. Tibiae and antennal scape matt, strongly microreticulate; short, erect setae present on antennal scape and metatibia and usually in whorls, length of longest setae < greatest width of tibia; gaster of minor worker strongly pubescent.

Melophorus sp. JDM 520

Tibiae and antennal scape lacking erect pilosity, moderately to strongly shining and smooth or with superficial microreticulation; gaster of minor worker without pubescence, often glabrous or nearly so

40. In profile, head of minor worker not dorsoventrally compressed, its side $0.7 \mathrm{x}$ as wide as long $\geq$ (Figure 64); in full-face view, eye set slightly above midpoint of gena; clypeal psammophore at about midpoint of clypeus; major worker with multiple preapical metatibial spurs; larger species (HW of major

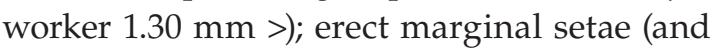
often non-marginal setae) present on gaster in minor worker 


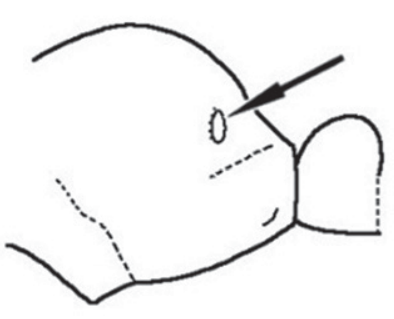

FIGURE 50

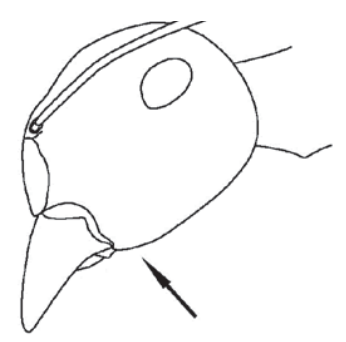

FIGURE 51

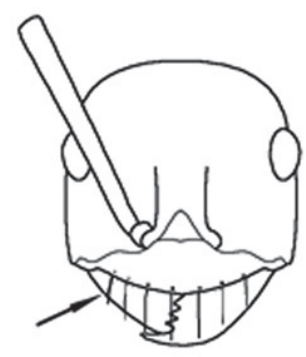

FIGURE 52

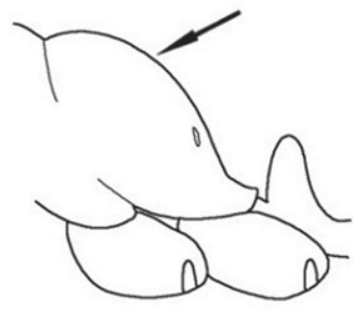

FIGURE 53

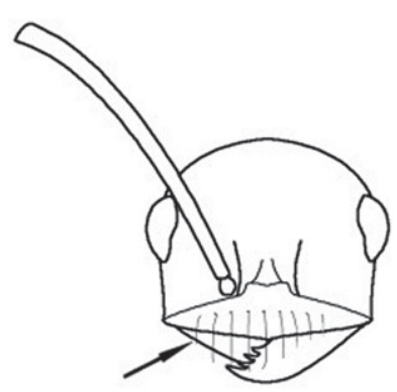

FIGURE 54

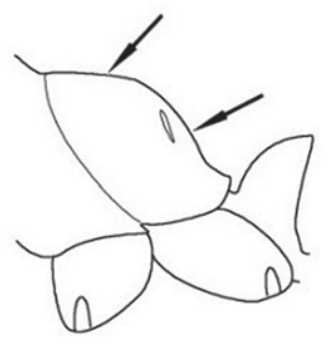

FIGURE 55

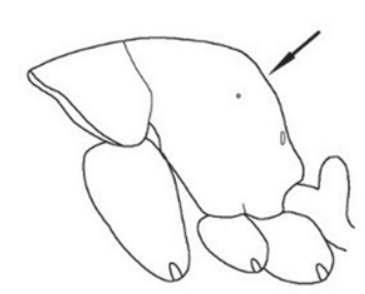

FIGURE 56

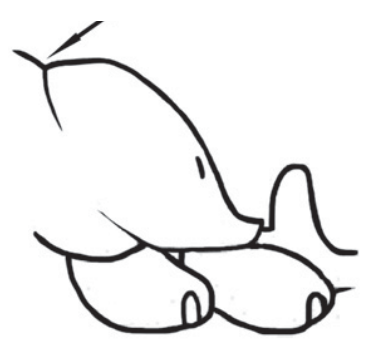

FIGURE 57

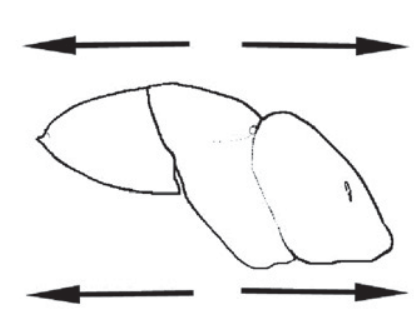

FIGURE 58

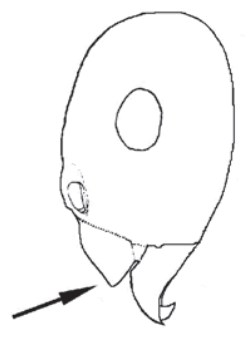

FIGURE 59

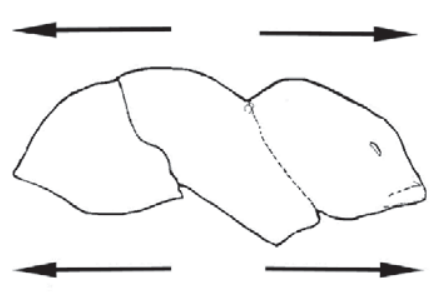

FIGURE 60

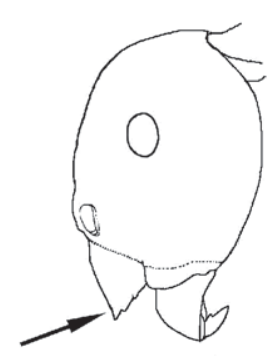

FIGURE 61

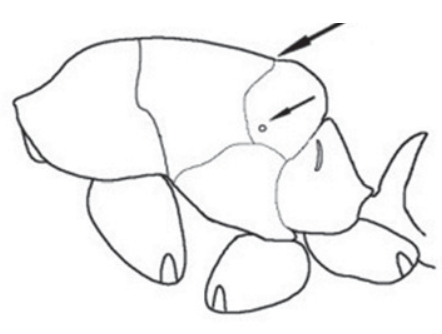

FIGURE 62

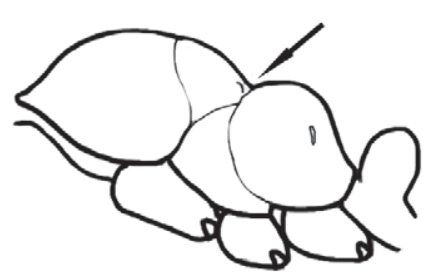

FIGURE 63

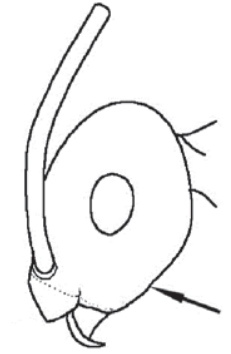

FIGURE 64 
In profile, head of minor worker dorsoventrally compressed, its side as little as $0.5 \mathrm{x}$ as wide as long (Figure 65); in fullface view, eyes set well above midpoint of gena; clypeal psammophore on or just above anterior clypeal margin in minor workers, placed just above anterior clypeal margin to midway between anterior clypeal margin and midpoint of clypeus in major workers; major worker with just one preapical metatibial spur; smaller species (HW of major worker $\leq$ $1.20 \mathrm{~mm}$ ); erect marginal and non-marginal setae lacking on gaster in minor worker

41. Colour of ant pale, depigmented yellow to bright orange-yellow in minor worker; concolorous orange-yellow or with darker gaster in major worker; in full-face view, colour of head capsule often two-toned, with orange-yellow above the anterior margin of the eye, and beige below the eye ..... Melophorus ludius sulla Forel

Colour various shades of brown, reddish brown or deep orange, concolorous or bicoloured with gaster always darker (often dark brown or black), but never as above. Melophorus turneri Forel

42. In full-face view, major worker with posterior clypeal margin not arched or falling away between antennal insertion and tentorial pit (Figure 66); anterior clypeal margin of major worker straight and never protuberant; major worker mesosoma with up to a dozen fine, flexuous erect setae; minor worker mesosoma glabrous, glossy, with superficial sculpture only; colour pale yellowish to brown, concolorous or with darker gaster....... Melophorus ludius Forel

In full-face view, major worker with posterior clypeal margin arched and falling away between antennal insertion and tentorial pit (Figure 67); anterior clypeal margin of major worker weakly convex or with anteromedial dimple indicated; major worker mesosoma with a few short, bristly or slightly clavate (but not flexuous) erect setae; minor worker mesosoma glabrous with some shagreenate sculpture and matt to moderately shining; bicoloured orange-and-brown to brown with darker gaster. Melophorus marius Forel

43. Mandible armed with six or seven teeth; antennal scape with erect setae (Nylanderia) .Nylanderia braueri glabrior (Forel)
Mandible armed with five teeth; antennal scape lacking erect setae. 44

44. Propodeum lacking erect setae (Figure 68); erect setae scattered over head capsule; femora and tibia with a few large, erect setae (Paratrechina)....

Paratrechina longicornis (Latreille)

One pair of erect setae present on propodeum (Figure 69): four erect setae on posterior margin of vertex, with two rows of paired erect setae extending from posterior margin of vertex to posterior clypeal margin; femora and tibiae lacking large erect setae (Paraparatrechina)

45. Eye elliptical, moderate in size (eye length $<0.3 \times$ head length (Figure 70); brownishyellow Paraparatrechina minutula (Forel)

Eye slightly asymmetrical, larger (eye length $\approx 0.3 \times$ head length) (Figure 71); depigmented yellow

Paraparatrechina minutula group sp. JDM 916

46. Apex of hypopygium with a narrow, laterally oriented slit that is situated ventrally (Figure 72); abdomen without an impression between the third and fourth abdominal segments; gastral cuticle often soft, flexible and easily collapsed (Dolichoderinae)

Apex of hypopygium with a sting (Figure 73); abdomen may be deeply impressed between third and fourth abdominal segments; cuticle stronger, less flexible and not normally collapsible.

47. Petiole without a distinct node (Figure 74); posterior margin of clypeus a broad, even arc (Tapinoma)..... 48

Petiole usually with a distinct node (Figure 75); if node weak, then posterior margin of clypeus elliptical or forming a shallow rectangle with median sector often more-orless straight.....

48. Eye large, eye length $\approx 1 / 3$ length of head capsule (Figure 76)

Tapinoma sp. JDM 981

Eye smaller, eye length $\leq 1 / 4$ length of head capsule (Figure 77).......... Tapinoma sp. JDM 78

49. Palps very short (PF 2,2) (Figure 78); eyes small (about 50 facets); clypeus with several to many downwardly curved setae, which are about the same length as the closed mandible (Arnoldius) Arnoldius sp. JDM 433 


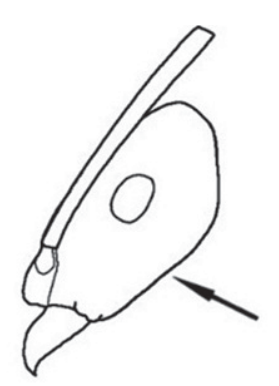

FIGURE 65

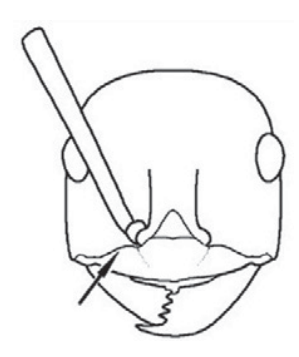

FIGURE 66

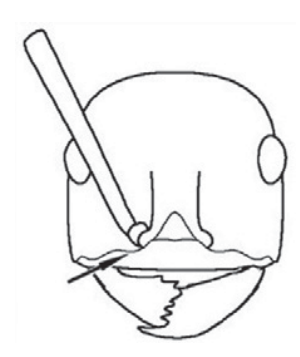

FIGURE 67

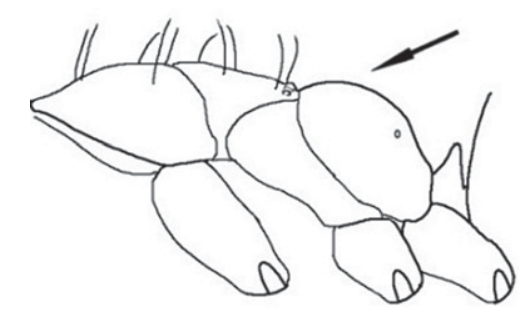

FIGURE 68

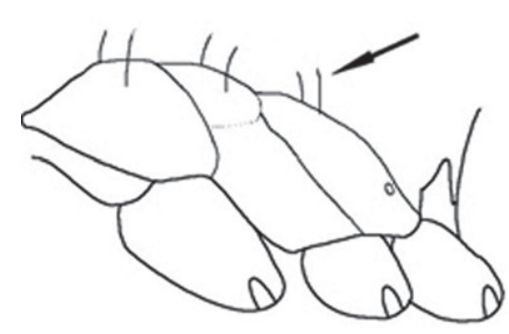

FIGURE 69

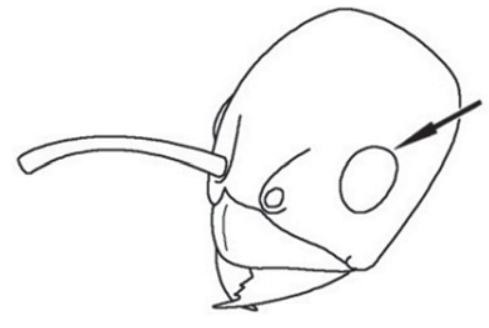

FIGURE 70

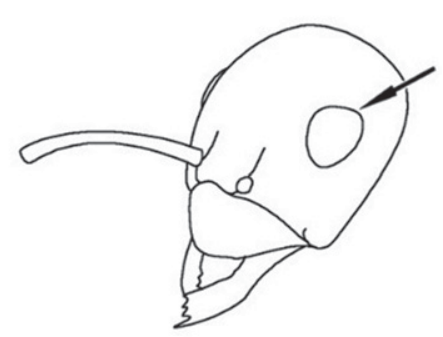

FIGURE 71

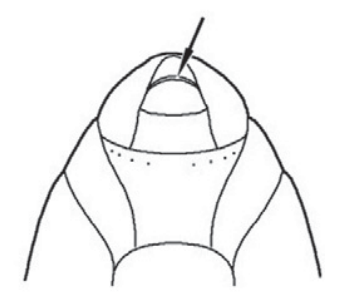

FIGURE 72

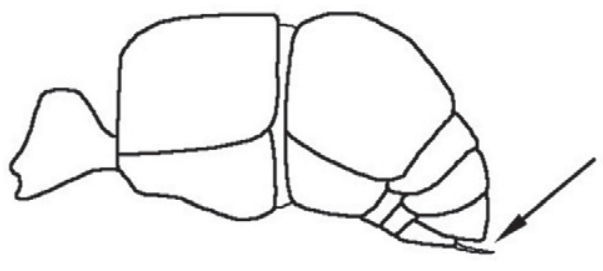

FIGURE 73

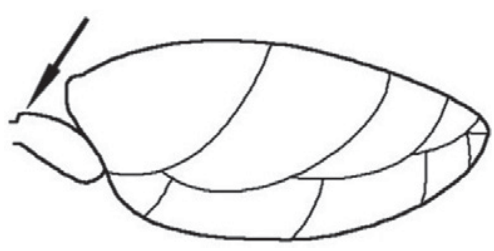

FIGURE 74

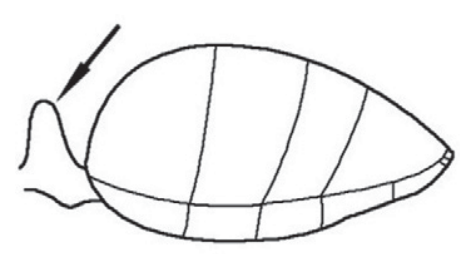

FIGURE 75

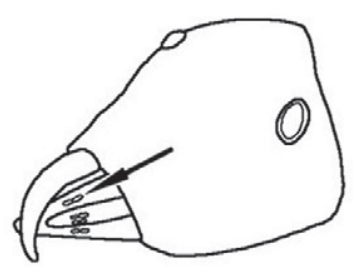

FIGURE 76

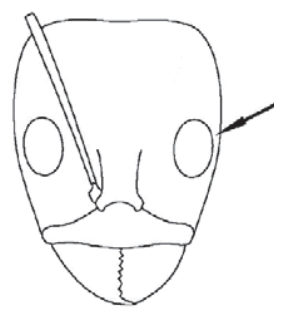

FIGURE 77

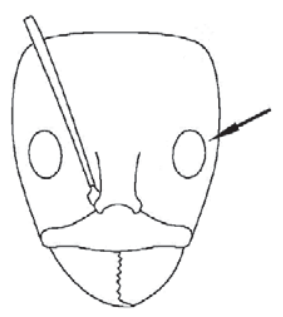

FIGURE 78 
Palps longer (PF 6,4) (Figure 79); eyes generally larger; clypeus with several to many short, occasionally curved setae that are shorter than the closed mandible. 50

50. Declivitous face of propodeum concave; gaster often shining with purple or blue iridescence (Figure 80); nearly always associated with wood or manmade structures (Ochetellus)

Declivitous face of propodeum never concave, usually rounded (e.g., Figure 81); if iridescent, then iridescence extended to mesosoma and head; northern Western Australian species nest terrestrially 52

51. In profile, propodeum vertically rectangular (propodeal length $\leq 0.40 \times$ propodeal width); in dorsal view, propodeum terminating in a tapered flange (Figures 82a, b) Ochetellus flavipes (Kirby)

In profile, propodeum square, about as long as high; in dorsal view, propodeum terminating in a squared-off flange (Figures $83 a, b)$. . Ochetellus sp. JDM 527

52. Mesosoma consisting of three compact segments, the two thoracic segments higher than long, the propodeum obliquely flattened (Figure 84); node indistinct, barely rising above the articulation of the peduncle with propodeum; small to minute ants (1-1.5 mm) (Doleromyrma)

. Doleromyrma rottnestensis Wheeler

Mesosoma less compact, the propodeum generally rounded or roundly cuboidal (e.g., Figure 85); petiolar node distinct; generally larger species (2-5 mm) (Iridomyrmex) .......... 53

53. In profile, petiolar node thick, very elongate and strongly inclined anteriad, the anterior face very short or even virtually absent (Figure 86); in full-face view, frontal carinae strongly concave (Figure 87) Iridomyrmex cephaloinclinus Shattuck

In profile, petiolar node not as above (Figure 88); frontal carinae weakly concave, straight or weakly convex (Figure 89) 54
54. Acute anteromedial clypeal prominence present as a conspicuous triangle (Figure 90); erect setae present on antennal scapes and hind femora, and often a few on sides of head; frontal carinae distinctly sinuate with small flanges on carinae often tending to angulate medially; metathoracic spiracles prominent (medium-large to large ants, often with broad, triangular heads and with weak pink or purplish iridescence on body and legs)

Anteromedial clypeal prominence not a conspicuous triangle (either a small blunt projection, an indistinct undulation of the cuticle or completely absent) (Figure 91) or erect setae absent from one or more of antennal scapes, sides of head and hind femora; frontal carinae rarely distinctly sinuate 56

55. Antennal scapes short $(\mathrm{SL}<1.30 \mathrm{~mm})$; in fullface view, anteromedial clypeal prominence shorter, not extending beyond lateral lobes of anterior clypeal margin; erect hairs on head and body fine and pale in colour........... Iridomyrmex discors Forel

Antennal scapes long (SL > 1.35mm); in fullface view, anteromedial clypeal prominence longer, extending beyond lateral lobes of anterior clypeal margin; erect hairs on head and body typically bristly and dark in colour. .Iridomyrmex sanguineus Forel

56. Semi-erect to erect setae present on antennal scapes and hind tibiae and, often, sides of head (a few hirsute populations of I. chasei that may occur on Barrow Island). Iridomyrmex chasei Forel (pt.)

Semi-erect to erect setae absent from antennal scapes, or hind tibiae, or both parts ............. 57

57. Hind tibiae with distinct erect and/or semi-erect setae in addition to appressed or decumbent setae (may be sparse) ...................58

Hind tibiae without erect/sub-erect setae .59

58. In full-face view, erect setae confined to posterior margin of head (Figure 92); erect setae on hind tibiae sparse, often confined to one or two (a few hirsute populations of $I$. anceps that may occur on Barrow Island) Iridomyrmex anceps (Roger) (pt.) 


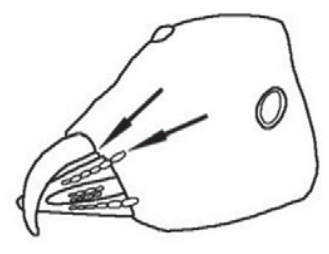

FIGURE 79

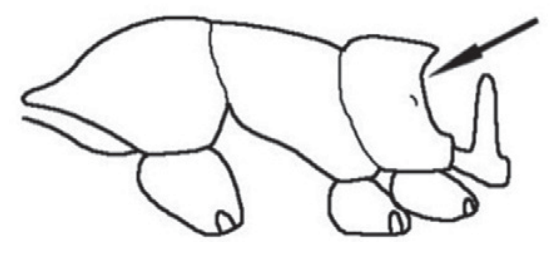

FIGURE 80

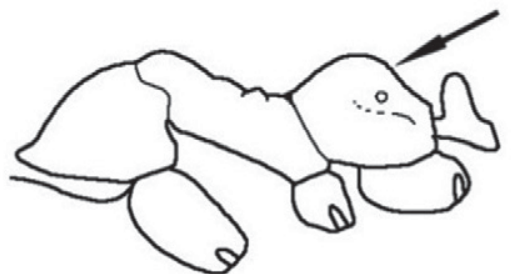

FIGURE 81
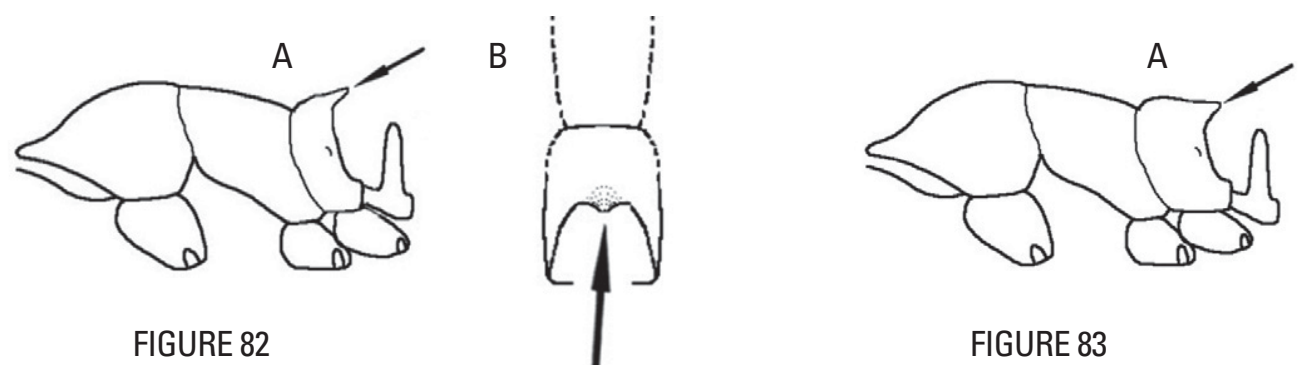

FIGURE 83

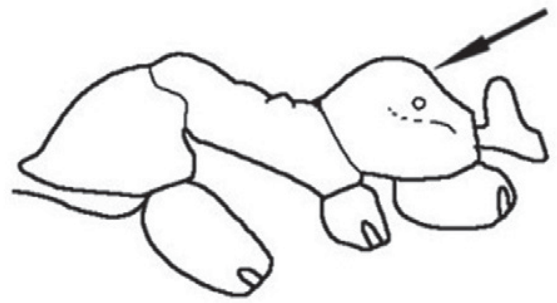

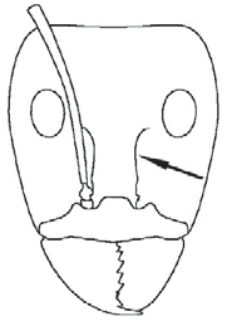

FIGURE 87

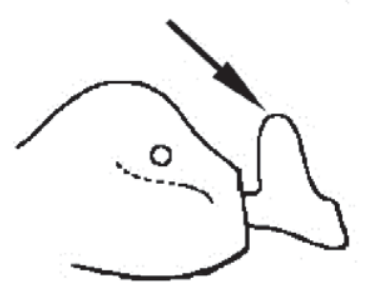

FIGURE 88
FIGURE 86

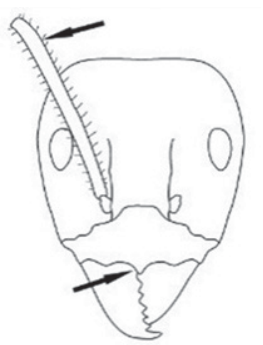

FIGURE 90

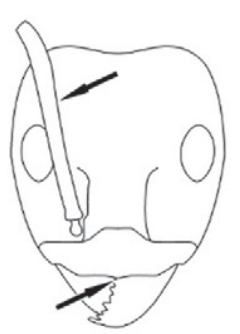

FIGURE 91
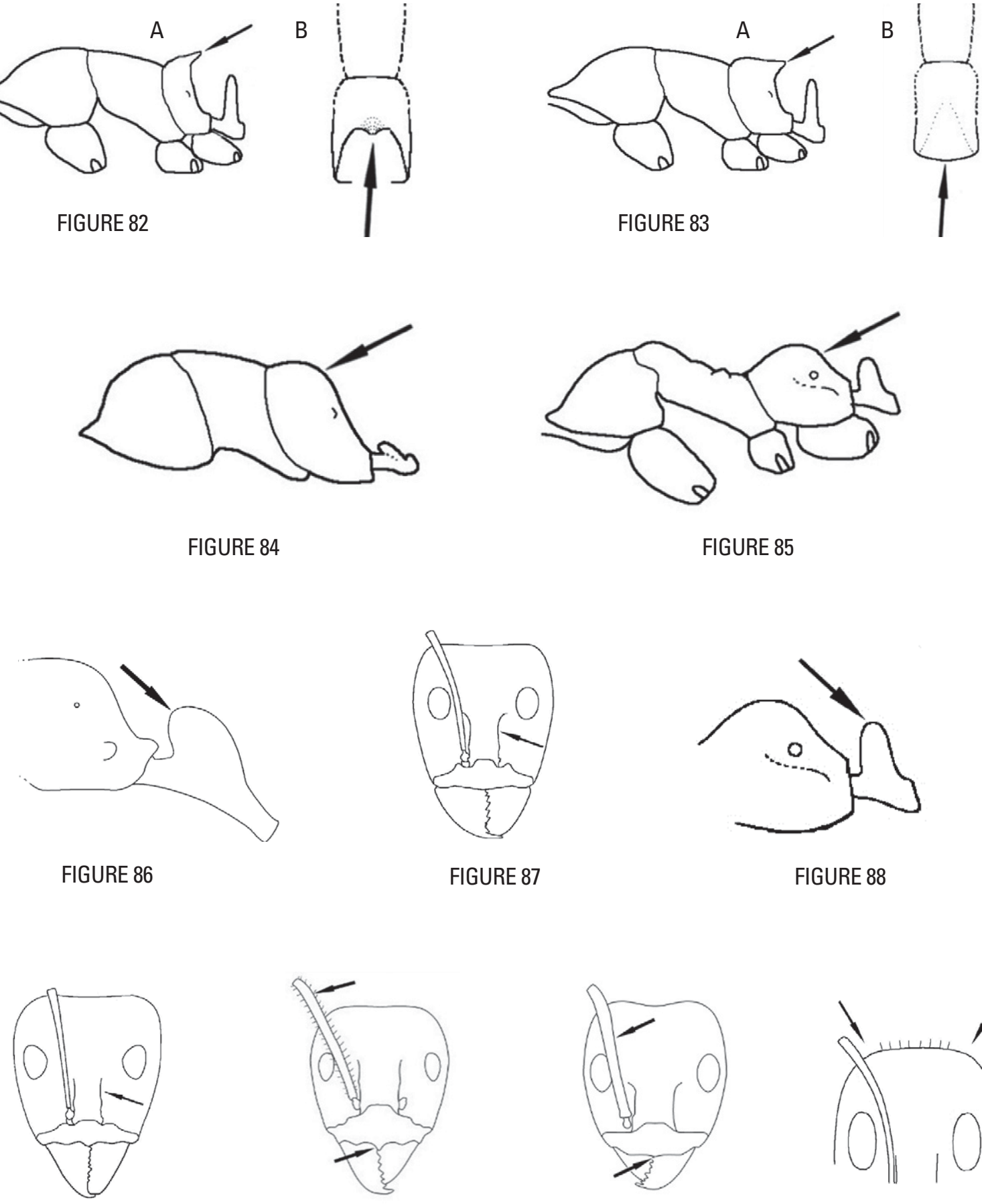

FIGURE 89
FIGURE 85

FIGURE 84
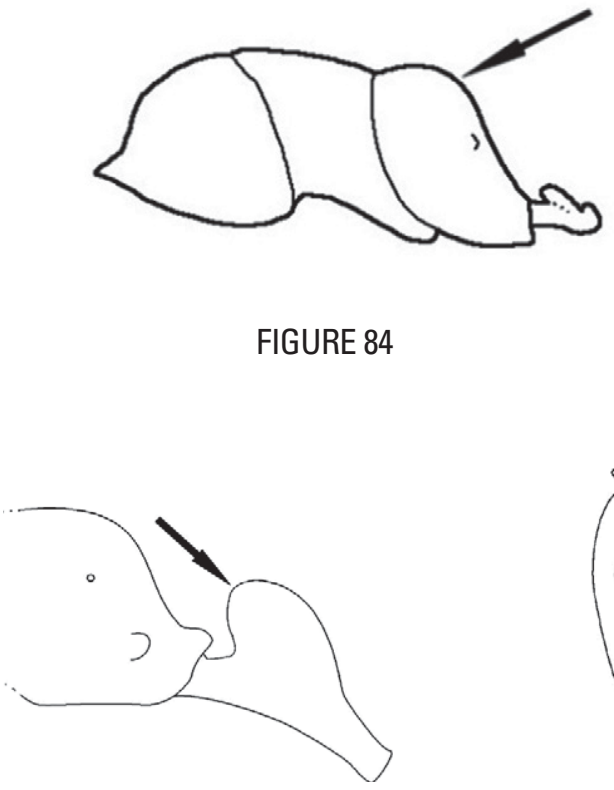
In full-face view, erect setae extending along lateral margins of head to at least the eyes (Figure 93); typically, erect setae on hind tibia moderately plentiful to abundant and extending along length of tibia (a few hirsute populations of I. minor that may occur on Barrow Island)

Iridomyrmex minor Forel (pt.)

59. Head in full-face view extremely narrow (CI 64-70); in dorsal view, pronotum very weakly tapering towards its anterior margin; eye large $(\mathrm{EL}>0.24 \mathrm{~mm}, \mathrm{EW}>0.19 \mathrm{~mm}, \mathrm{EI}>38$, eye width greater than or equal to $3 \times$ greatest diameter of antennal scape).....

Iridomyrmex tenuiceps Heterick and Shattuck

Without above combination of three characters (in I. agilis, which is similar, the eye is smaller).... 60

60. Head in full-face view elongate (CI < 83), upper vertex rather broad above eyes (Figure 94); in the same view, eyes placed at about midpoint of head; margin of clypeus produced as a sharp, narrowly triangular tooth; hind femur very long, length greater than or equal to mesosoma Iridomyrmex agilis Forel

If head elongate, length of hind femur less than length of mesosoma or, in full-face view, eyes placed above midpoint of head and upper vertex narrow compared with region below eyes (e.g., Figure 95), and anteromedial clypeal margin not produced as a sharp, narrowly triangular tooth 61

61. Eye with distinctly protuberant anteromedial margin, and a posterior lobe that is narrower than its anterior lobe (Figure 96); colour of ant most commonly depigmented or tawny yellow, but never iridescent. .62

Eye with, at most, a slightly protuberant anteromedial margin, and a posterior lobe that is not narrower than its anterior lobe (Figure 97); ant shades of reddish-brown, brown or black (bicoloured or concolorous), and may have iridescence. .64

62. Erect hairs short, pronotal and mesonotal hairs six <, often mesosoma glabrous; in profile, propodeum strongly protuberant; in full-face view, posterior margin of head weakly to strongly concave
Mesosoma with six $\geq$ erect setae, seta often numerous; in profile, propodeum may be smoothly rounded rather than protuberant; posterior margin of head generally slightly convex or planar, but may be very weakly concave.....

63. Propodeal dorsum rounding on to declivitous face through a protuberance (Figure 98) Iridomyrmex exsanguis Forel

Propodeal dorsum evenly rounded on to declivitous face without a protuberance (Figure 99) ............. Iridomyrmex dromus Clark

64. Antennal scape surpassing posterior margin of head capsule by at least $3 x$ its width and often $6 \mathrm{x}$ its width; vertex of head capsule slightly convex to very weakly concave; mesosoma gracile with propodeum that is an elongate curve in profile.....

Antennal scape surpassing posterior margin of head capsule by $2 x$ its width $\leq$; vertex of head may be deeply concave; mesosoma more compact, in profile often with truncate and raised propodeum 66

65. Concolorous brown to dark brown, often with coppery reflections; hairs on pronotum and mesonotum short and bristly, their length not exceeding greatest diameter of the eye; length of hind femur variable, but usually less than $0.90 \times$ length of mesosoma Iridomyrmex anceps (Roger) (pt.)

Not concolorous brown (generally, gaster darker than body, and head and foreparts often with varying degrees of reddish or orange coloration); length of hairs on pronotum and mesonotum often exceeding greatest diameter of the eye; length of hind femur greater than or equal to $0.90 \times$ length of mesosoma .......... Iridomyrmex minor Forel (pt.)

66. In full-face view, posterior margin of head broadly concave, posterolateral corners broadly angulate (Figure 100); in profile, anterior pronotum humped, arising steeply at angle of $\approx 60^{\circ}$; propodeum narrowly protuberant (Figure 101); head and mesosoma without iridescence; if gaster with blue-green reflections then ground colour of gaster black and foreparts bright orange with or without some brown infuscation, gaster usually with coppery reflections only; pronotum usually with $10>$ erect setae, never glabrous Iridomyrmex chasei Forel (pt.) 
In full-face view, posterior margin of head usually planar (Figure 102), but if broadly concave and posterolateral corners broadly angulate, then ant blackish or dark brown with faint to strong blue-green, yellow-green or pinkish iridescence; anterior pronotum not so steeply humped, arising at $45^{\circ} \leq$, and its dorsum may be glabrous (Figure 103) .. 67
67. In profile, ant very compact; anterior pronotum humped, arising at angle of $\approx 45^{\circ}$ and descending as a steep and symmetrical curve (Figure 104); propodeum narrowly protuberant and truncate with a planar dorsum; head and mesosoma never iridescent; concolorous plain brown species .......Iridomyrmex gibbus Heterick and Shattuck

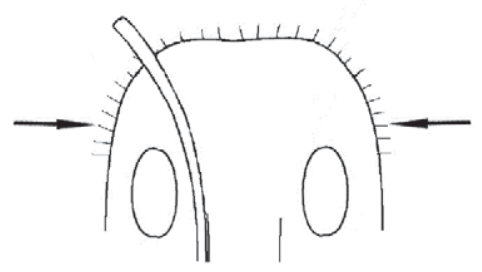

FIGURE 93

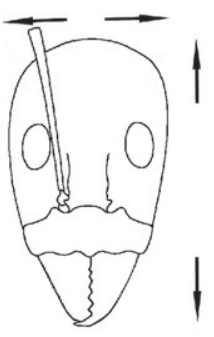

FIGURE 94

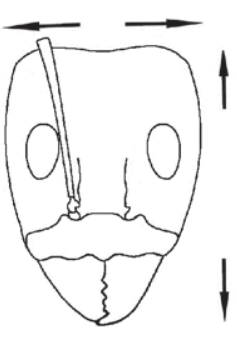

FIGURE 95

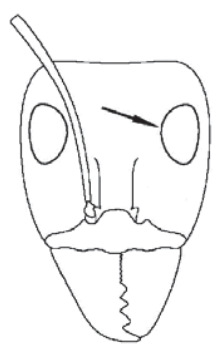

FIGURE 96

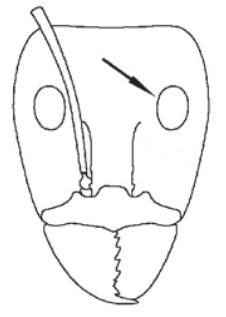

FIGURE 97

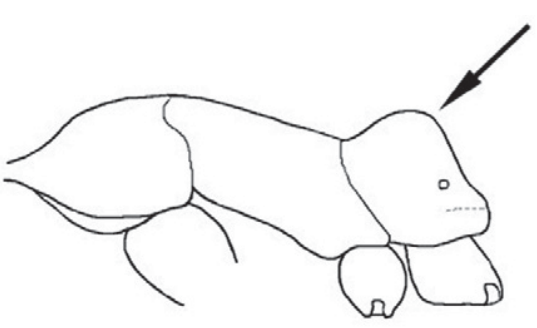

FIGURE 98

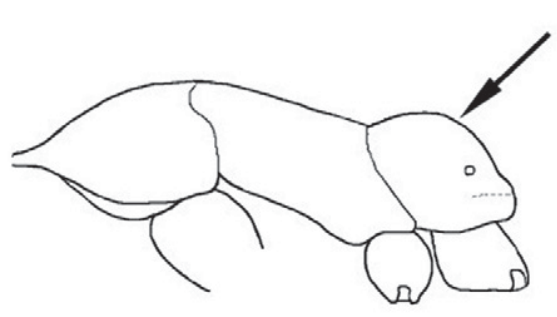

FIGURE 99

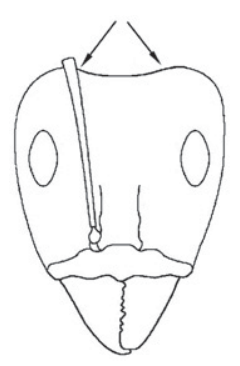

FIGURE 100

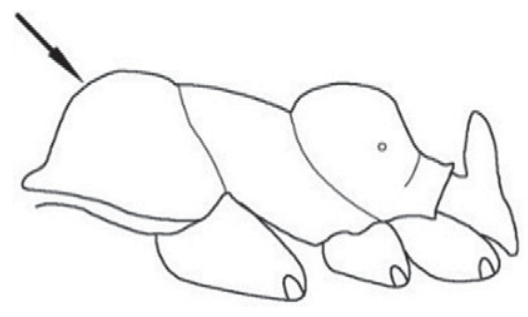

FIGURE 101

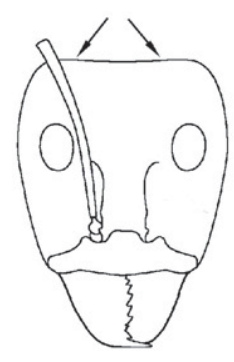

FIGURE 102

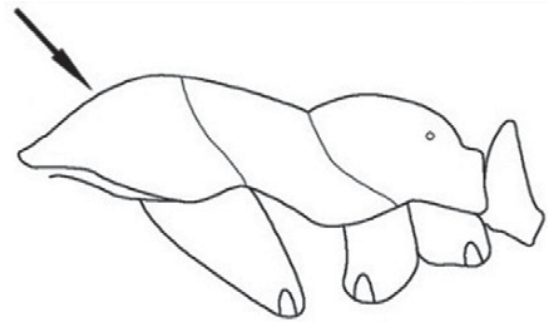

FIGURE 103

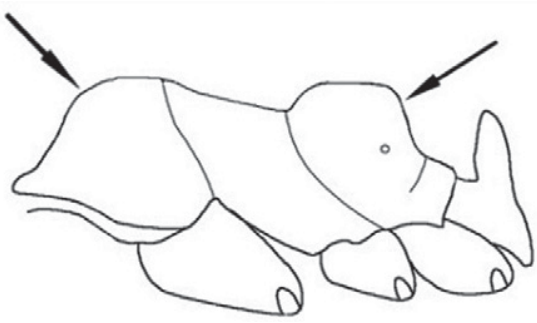

FIGURE 104 
In profile, ant less compact; anterior pronotum usually arising as a smooth curve at angle $\leq 30^{\circ}$ (Figure 105); in profile, propodeum often broadly rounded, but if rectangular then its dorsum rounded in Barrow Island populations; head and mesosoma usually with some iridescence, either bluish, yellowgreen or pinkish (I. coeruleus) or coppery (I. mjobergi).. .68

68. Dorsum of mesosoma with short, bristly whitish setae; iridescence distinct and bluish in Barrow Island populations

Iridomyrmex coeruleus Heterick and Shattuck

Dorsum of mesosoma either glabrous or with a few short, dark, bristly setae; weak, coppery iridescence only in Barrow Island populations.....Iridomyrmex mjobergi Forel

69. Petiole broadly articulated to abdominal segment III; dentiform clypeal setae present (Figure 106) (Amblyoponinae) Amblyopone sp. indet. (a single male ant)

Petiole with distinctly descending posterior face; dentiform clypeal setae absent (Figure 107) 70

70. In profile, metapleural gland orifice a longitudinal to oblique curved slit or crescent, directed upward by a strip of cuticle (Figure 108) (Ectatomminae) ..... . .71

In profile, metapleural gland orifice elliptical to circular and opening laterally or posteriorly, not bounded by strip of cuticle that directs orifice upward (Figure 109) ........ 74

71. In full-face view, angles of vertex of head capsule produced as distinct, raised denticles (Figure 110)........... Rhytidoponera taurus (Forel)

In full-face view, angles of vertex of head capsule more-or-less rounded angles (Figure 111). .72

72. Hind tibial spur highly reduced and difficult to distinguish from surrounding spines; apex of petiolar node terminating in a sharp spur (usually) or a dull point (rarely) directed posteriad (Figure 112)...... .......Rhytidoponera tyloxys Brown and Douglas
Hind tibial spur present and distinct; apex of petiolar node planar or tapered and lacking a process or point directed posteriad (e.g., Figure 113). .73

73. In profile, petiolar node thick and cuboidal or sub-cuboidal (Figure 114). .Rhytidoponera crassinoda (Forel)

In profile, petiolar node thin and tapered towards its apex (Figure 115)

Rhytidoponera?micans complex sp. JDM 1129

74. Promesonotal suture either completely absent or present and reduced and fully fused, so pronotum and mesonotum are incapable of independent movement (Figure 116); antennal sockets mostly to completely exposed (Figure 117) (Proceratiinae) .75

Promesonotal suture fully developed, so pronotum and mesonotum capable of independent movement (Figure 118); antennal sockets covered by developed frontal lobes (Figure 119) (Ponerinae) .76

75. Second gastral tergite strongly arched so that succeeding segments are ventral and oriented anteriad towards the head end of the ant (Figure 120) (Discothyrea) ....... Discothyrea sp. JDM 1130 (a single queen)

Second gastral tergite only very weakly arched, successive segments oriented posteriad (Figure 121) (Probolomyrmex)... Probolomyrmex latalongus (Shattuck, Gunawardene and Heterick) (a single queen)

76. Mandibles long and linear, inserted in central anterior margin of head (Figure 122) .............77

Mandibles triangular or elongate, curved, inserted at sides of head (Figure 123) ............ 79

77. Top of head with V-shaped lines converging to form a groove on upper front of head (Figure 124) (Odontomachus). . Odontomachus ruficeps F. Smith

Top of head without V-shaped lines and with broad, uninterrupted curved ridge; weak groove present or absent (Figure 125) (Anochetus). 


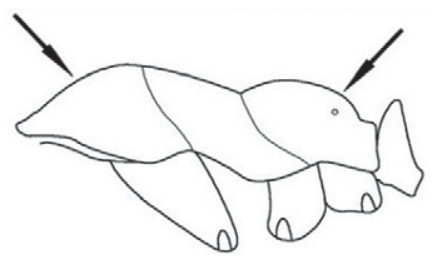

FIGURE 105

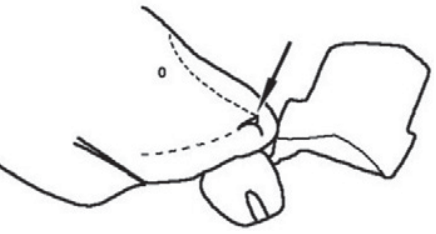

FIGURE 108

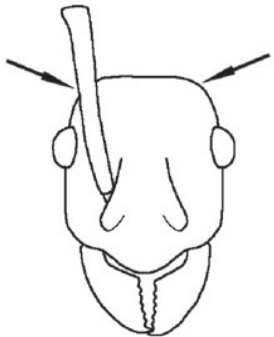

FIGURE 111

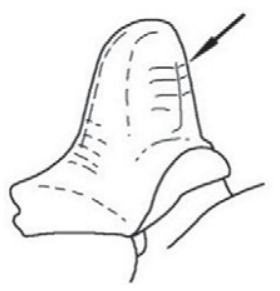

FIGURE 115

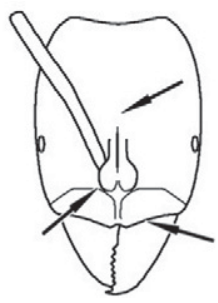

FIGURE 119

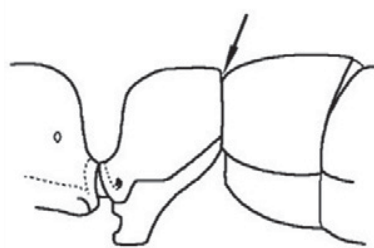

FIGURE 106

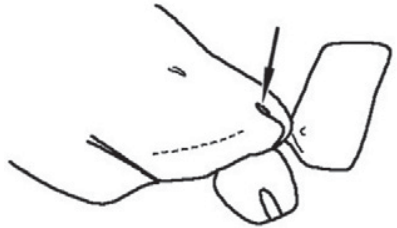

FIGURE 109

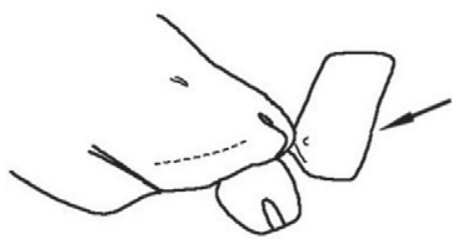

FIGURE 107

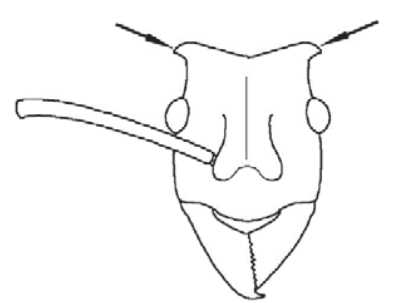

FIGURE 110

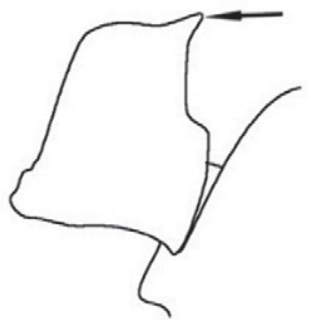

FIGURE 112

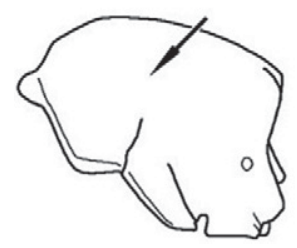

FIGURE 116

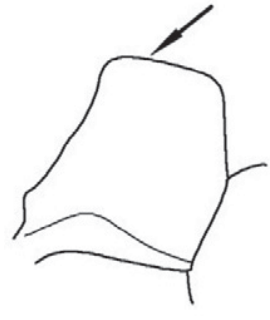

FIGURE 113

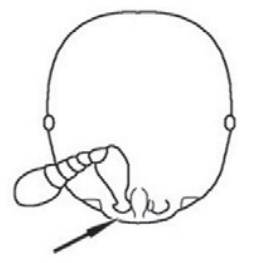

FIGURE 117

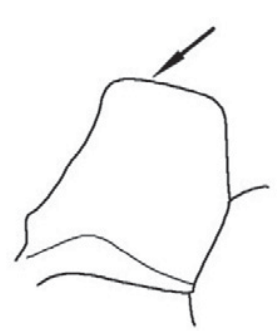

FIGURE 114

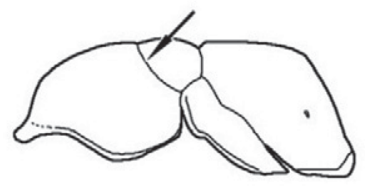

FIGURE 118

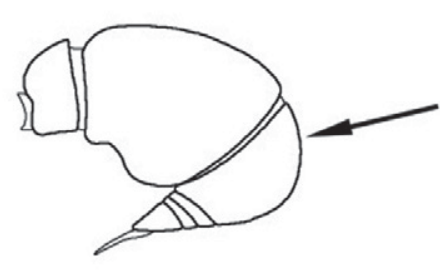

FIGURE 120

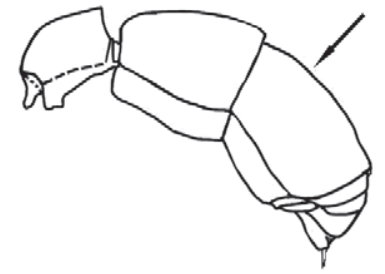

FIGURE 121

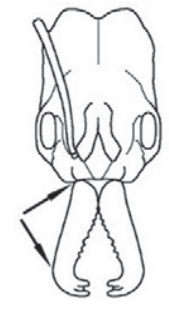

FIGURE 122

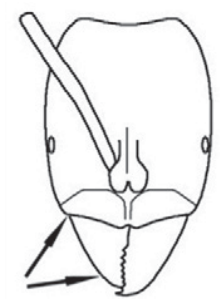

FIGURE 123

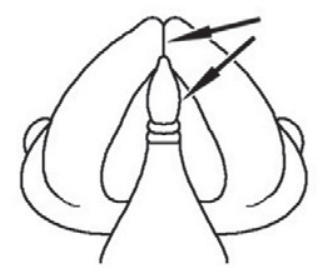

FIGURE 124

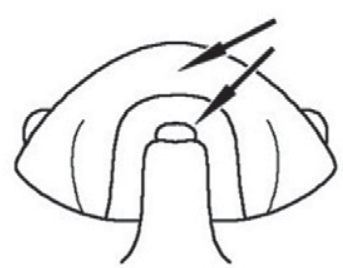

FIGURE 125 
78. Entire pronotum and sides of propodeum smooth and shining; dorsal surface of propodeum with weak transverse striations (nearly absent in some specimens); setae on dorsal surface of propodeum very short, scattered and appressed

Anochetus renatae Shattuck

Pronotum partially to completely sculptured; sides of propodeum with coarse striations, dorsal surface coarsely sculptured with combination of irregular rugosity and striations; setae on dorsal surface of propodeum longer, erect or semi-erect..... Anochetus rectangularis Mayr

79. Pretarsal claws of hind leg equipped with one or more teeth on the inner curvature, and usually pectinate: clypeus produced anteriad as an acute, V-shaped projection (Figure 126) (Leptogenys). 80

Pretarsal claws of hind leg simple; clypeus straight or broadly convex; not produced anteriad as an acute, V-shaped projection (Figure 127) .81

80. In full-face view, mandibles curved, elongate; eyes of normal appearance; cuticle of head, mesosoma and petiolar node with many shallow foveae; dark brown to blackish ants Leptogenys sp. JDM 1128

In full-face view, mandibles narrowly triangular, their blades parallel; eyes vestigial; cuticle of head, mesosoma and petiolar node smooth and glossy; orange ants Leptogenys cf. tricosa Taylor

81. Tibia of hind leg with a single large pectinate spur (Figure 128) (Hypoponera).

Hypoponera sp. JDM 1142

Tibia of hind leg with both a single large pectinate spur and a smaller, simple spur (Figure 129) (Pachycondyla) .82

82. Larger species ( $\mathrm{HW} \geq 2 \mathrm{~mm}$ ); heavily sculptured ...... Pachycondyla denticulata (Kirby)

Smaller species $(\mathrm{HW} \approx 1 \mathrm{~mm})$; at most, weakly sculptured ............... Pachycondyla lutea (Mayr)

83. Eyes absent or represented by a single facet; frontal lobes absent, so that the antennal insertions are completely exposed (Figure 130) .84

Eyes normally present, but if absent, frontal lobes expanded so that the latter cover all or part of the antennal insertions (Figure 131)
84. Pronotum and mesonotum fused to form one segment; antennae 10-segmented (Figure 132); length 3mm > (Aenictinae: Aenictus) ..... .Aenictus turneri Forel

Joint between pronotum and mesonotum flexible; antennae 12-segmented (Figure 133); length $2.5 \mathrm{~mm}<$ (Leptanillinae: Leptanilla) ..... Leptanilla swani Wheeler (males only collected on Barrow Island)

85. Joint between pronotum and mesonotum flexible (Figure 134): hind tibiae with pectinate spurs; tarsal claws toothed (Figure 135) (Pseudomyrmecinae: Tetraponera)..... Tetraponera punctulata F. Smith

Pronotum and mesonotum fused to form one segment (the promesonotum) (Figure 136); hind tibiae with at most a simple spur, but this may be lacking; tarsal claws simple (Figure 137) (Myrmicinae).... .86

86. Distinctive ant with triangular, deeply emarginate head; antennal segments $\leq$ six; mandible curved, elongate and armed at the tip with intersecting spikes (Figure 138) (Strumigenys) ........... Strumigenys sp. JDM 1230

Ant not as above; head more rounded (Figure 139); antennal segments $\geq$ nine; mandible triangular. 87

87. Antenna with nine segments; dorsum of anterior mesosoma flattened and projecting to form a shield, often with regular protruding edges and translucent 'windows' between these edges (Figure 140) (Meranoplus) ........... 88

Antenna with 10 or more segments; dorsum of mesosoma never forming a shield as above

88. In full-face view, clypeus strongly incurved, weakly tapered anteriad, emarginate in appearance and extended only slightly beyond the apices of the antennal lobes; antennal lobes broad, often hiding most of the eye (Figure 141) 89

In full-face view, clypeus weakly incurved, moderately to strongly tapered anteriad with a straight anteromedial margin and extended well beyond the apices of the antennal lobes; antennal lobes narrower, so eye can often be clearly seen (Figure 142)...... .90

89. In full-face view, sculpture of head capsule with vestigial, minute, dense longitudinal striae that are almost invisible; in profile, petiolar node subcuboidal, its dorsum planar (Figure 143)..... Meranoplus fenestratus F. Smith 


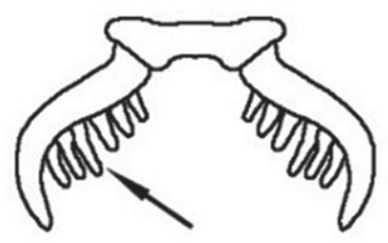

FIGURE 126

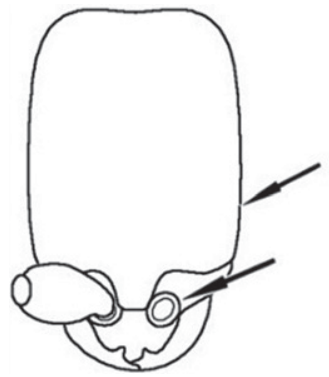

FIGURE 130

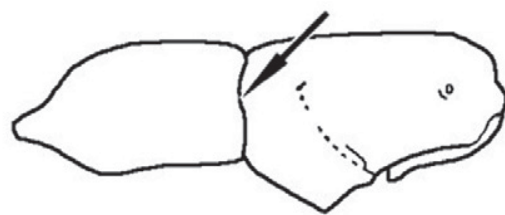

FIGURE 133

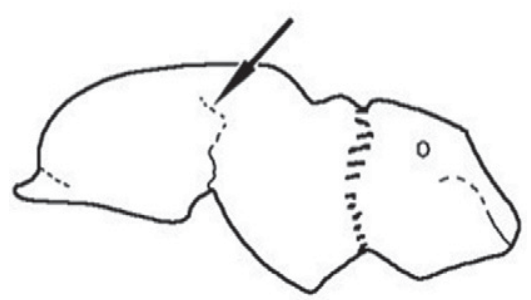

FIGURE 136

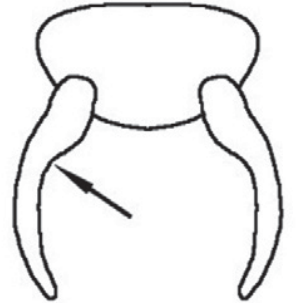

FIGURE 127

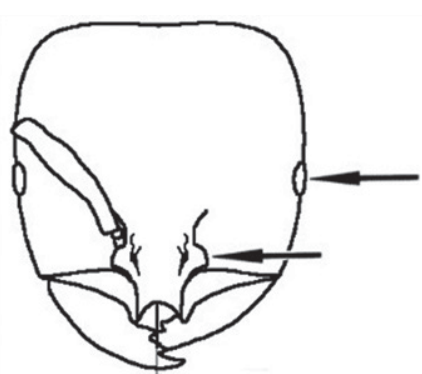

FIGURE 131

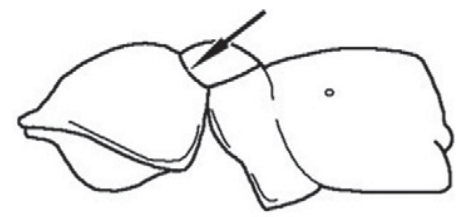

FIGURE 134

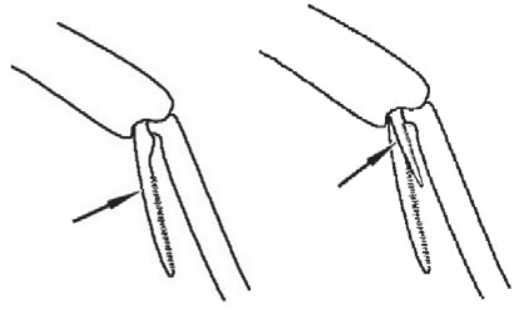

FIGURE 128

FIGURE 129

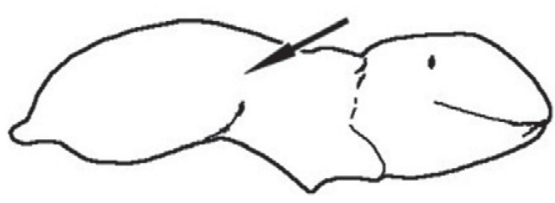

FIGURE 132

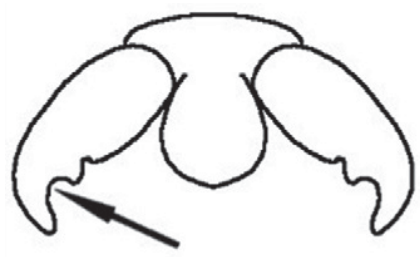

FIGURE 135

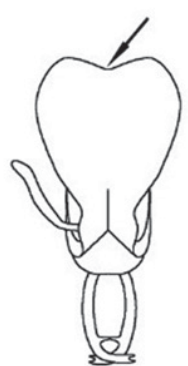

FIGURE 138

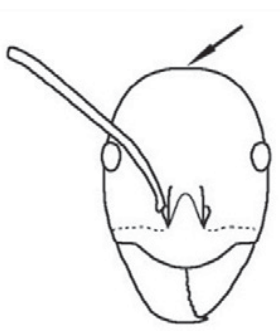

FIGURE 139

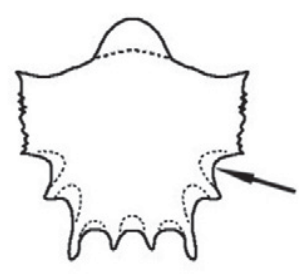

FIGURE 140

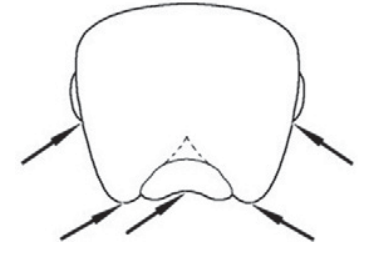

FIGURE 141

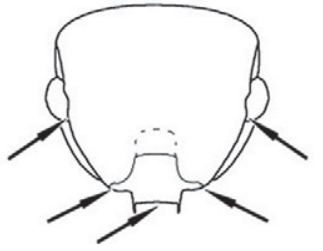

FIGURE 142

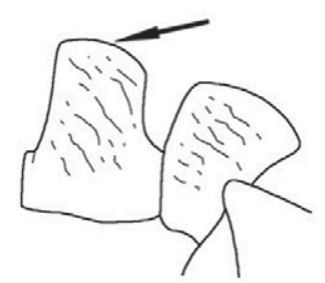

FIGURE 143 
In full-face view, sculpture of head capsule consisting of distinct, evenly spaced longitudinal striae; in profile petiolar node narrow and tapering, its dorsum rounded (Figure 144)................ Meranoplus sp. JDM 268

90. In dorsal view, promesonotal shield without spines or a flange on its posterior margin (Figure 145) ...... Meranoplus dimidiatus F. Smith

In dorsal view, promesonotal shield with spines on its posterior margin joined by at least a small flange (Figure 146) 91

91. In rear view, posterior face of petiolar node with a series of $\mathrm{v}$-shaped striae contained within each in a nested pattern; postpetiole also striate (Figure 147).....

.Meranoplus sp. JDM 865

In rear view, at least dorsum of posterior face of petiolar node foveate; postpetiole also foveate (Figure 148). .92

92. In dorsal view, posterolateral spines of promesonotal shield the most prominent, the posterior angles represented by narrower and usually shorter spines (Figure 149). Meranoplus sp. JDM 889

In dorsal view, spines at the posterior angles of promesonotal shield the most prominent, the posterolateral spines broader but much shorter than the former (Figure 150)

Meranoplus sp. JDM 1133

93. Postpetiole attached to upper surface of gaster, which is heart-shaped when seen from above; petiole flattened; viewed from above, postpetiole often distinctively bilobed (Figure 151) (Crematogaster) . .94

Postpetiole attached to the front of the gaster, which is not distinctively heart-shaped; petiole usually with a node, not flattened; postpetiole not bilobed as above (e.g., Figure 152)

94. Propodeum flattened and all sectors on the same plane (except for a narrow strip behind the metanotal groove); anterior lateral propodeal carinae present, extending from metanotal groove to propodeal angles (Figure 153) (subgenus Orthocrema)....

Crematogaster sp. JDM 1132

Anterior sector of propodeum not flattened, often convex, not on same plane as posterior sector; anterior lateral propodeal carinae always absent (Figure 154)..... ..Crematogaster laeviceps chasei Forel
95. First and second antennal segments much longer than remaining segments and forming a distinct two-segmented club (Figure 155)

Antennae either without a distinct club or with a three-segmented club (Figure 156)

96. Rear face of propodeum with flanges (Figure 157); clypeus with a pair of setae that straddle the midpoint of the anterior clypeal margin (Figure 158); strongly dimorphic, major workers with a pair of short horns on the vertex of the head capsule in some Eastern states species (Carebara) (a single minor worker). Carebara sp. JDM 1131

Rear face of propodeum rounded, never with teeth, spines or flanges (Figure 159); midpoint of anterior clypeal margin with a single seta (Figure 160); WA species weakly polymorphic (Solenopsis)

97. Eye absent or represented by a minute, pigmented speck (Figure 161). Solenopsis belisarius Forel

Eye small but distinct (Figure 162) ..Solenopsis clarki Crawley

98. Viewed from front, area of clypeus below antennal sockets raised into a sharp ridge (Figure 163); tip of sting with a triangular or club-like appendage projecting upwards from the shaft (Figure 164); propodeal angle usually a pair of stout spines, sometimes flanges (Tetramorium)

Viewed from front, area of clypeus below antennal sockets smooth or a dull ridge (Figure 165); tip of sting thin and pointed, occasionally slightly flattened, but without appendage; propodeal angle often absent or with pair of protuberances only (Figure 166)

101

99. Viewed in profile, petiolar node produced as a spur directed posteriad (Figure 167); lateral margins of first gastral tergite flattened to form flanges ....... Tetramorium spininode Bolton

Viewed in profile, petiolar node cuboidal and not produced as a spur directed posteriad (Figure 168); lateral margins of first gastral tergite rounded towards their junction with first ventral plate of gaster (sternite) ........... 100

100. Viewed in profile, gross sculpture of mesosoma consisting almost exclusively of parallel striae, the cuticle between them deeply incised (Figure 169); larger species $(\mathrm{HW} 1.20 \mathrm{~mm}>$ )......Tetramorium sjostedti Forel 


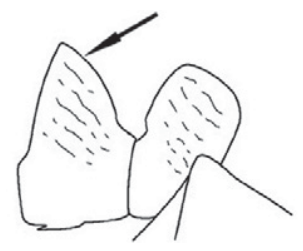

FIGURE 144

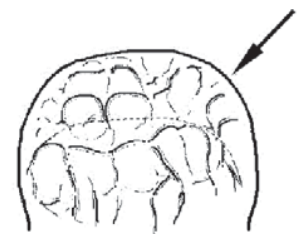

FIGURE 148

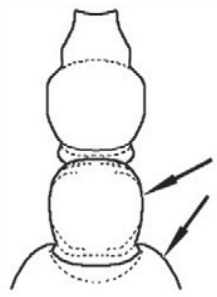

FIGURE 152

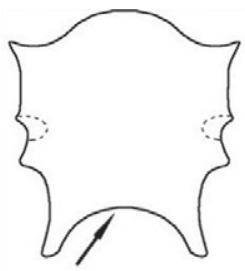

FIGURE 145

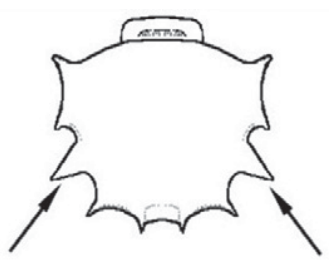

FIGURE 149

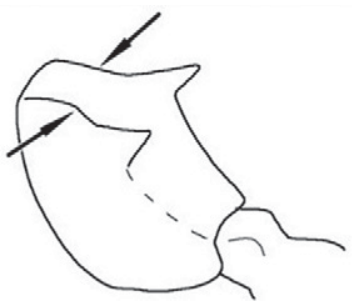

FIGURE 153

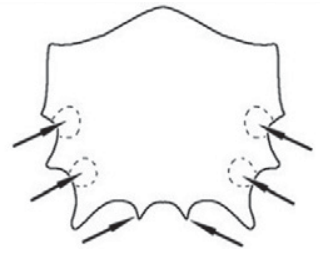

FIGURE 146

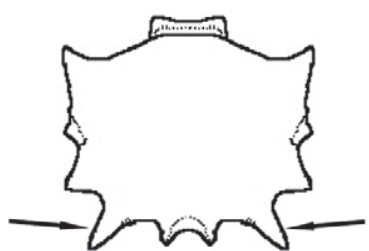

FIGURE 150

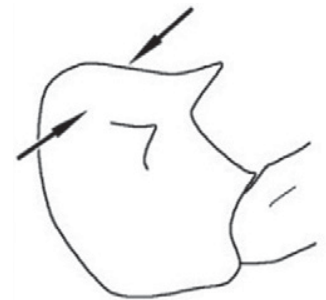

FIGURE 154

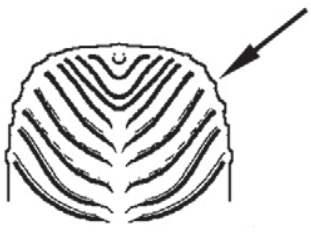

FIGURE 147

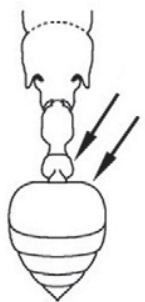

FIGURE 151

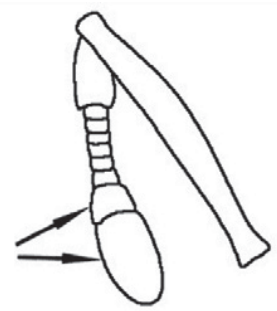

FIGURE 155

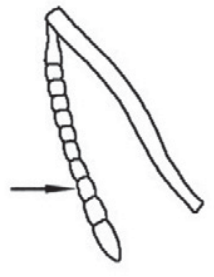

FIGURE 156

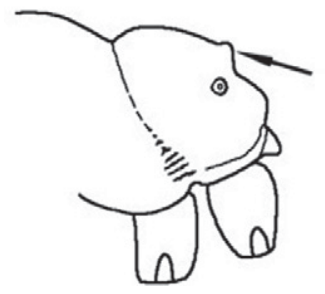

FIGURE 157

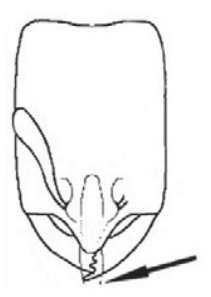

FIGURE 158

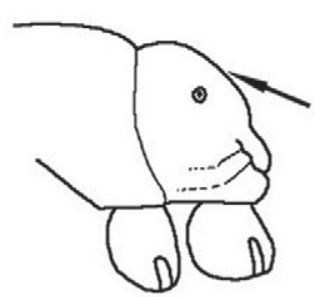

FIGURE 159

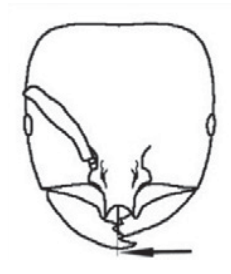

FIGURE 160

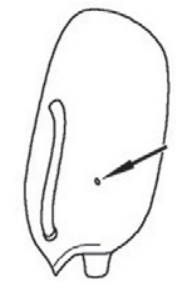

FIGURE 161

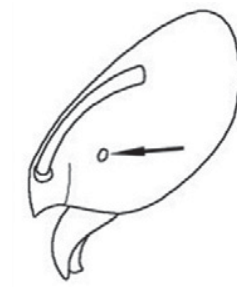

FIGURE 162

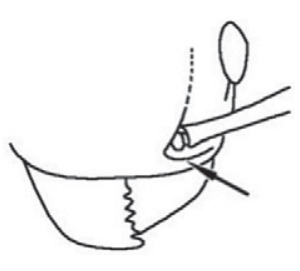

FIGURE 163

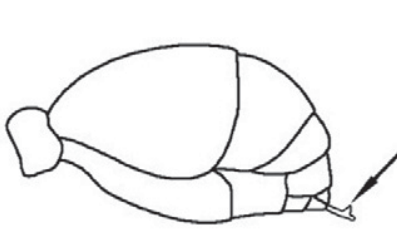

FIGURE 164

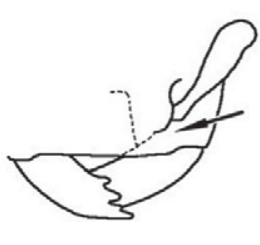

FIGURE 165

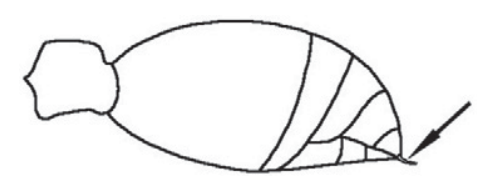

FIGURE 166

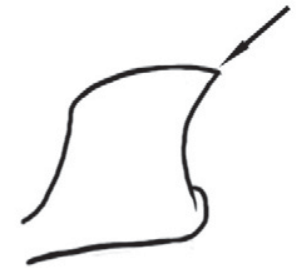

FIGURE 167

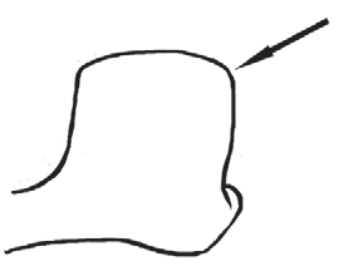

FIGURE 168

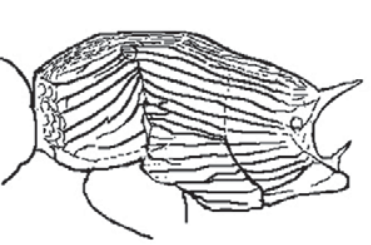

FIGURE 169 
Viewed in profile, gross sculpture of mesosoma consisting of a mixture of parallel striae, costulate sculpture and microreticulation, the cuticle between the gross sculpture not markedly incised (Figure 170); smaller species (HW $1.10 \mathrm{~mm}<$ ). ..Tetramorium striolatum Viehmeyer

101. Central anterior margin of clypeus with a single seta, which is often surrounded by paired setae (Figure 171); monomorphic or weakly polymorphic (i.e., exhibiting monophasic allometry) except for Monomorium euryodon..... 102

Central anterior margin of clypeus with paired setae or undifferentiated setae (Figure 172); strongly dimorphic (Pheidole).... .116

102. PF 5,3; clypeus plate-like, projecting and recessed posteriorly towards tentorial pits, (indented points of attachment of internal muscles), clypeus not bicarinate (Figure 173) (Cardiocondyla) 103

PF 2,3, 2,2 or 1,2; clypeus not plate-like or recessed posteriorly towards tentorial pits, clypeus often bicarinate (Figure 174) (Monomorium). 104

103. Head and mesosoma of worker matt or weakly shining, uniformly microreticulate; in rear view, rows of appressed gastral setae longer, often overlapping preceding and succeeding rows (one queen)

.Cardiocondyla nuda (Mayr)

Head and mesosoma of worker moderately shining, the underlying microreticulate pattern effaced in places, particularly on the humeral angles, the petiolar node and the postpetiole; in rear view, appressed gastral setae shorter, often separated from preceding and succeeding rows by $0.5-1 \times$ their own length..... Cardiocondyla atalanta Forel

104. Antenna with 11 segments . 105

Antenna with 12 segments..... 112

105. Viewed in profile, eye distinctly oblique, often reaching to venter of head capsule, distance from head capsule usually much less than length of eye (Figure 175) Monomorium eremophilum Heterick

Viewed in profile, eye situated along longitudinal axis of head, distance from mandible at most only slightly less than length of eye (Figure 176). 106
106. Propodeum more-or-less rounded, with small, inconspicuous metapleural lobes (Figure 177); propodeal and mesopleural sculpture never shagreenate-punctate, usually absent, if present, confined to a few striae, particularly around the katepisternum...... 107

Propodeum distinctly cuboidal, or with propodeal lobes lamellate and extending to near propodeum; propodeal and mesopleural sculpture may be shagreenate-punctate (Figure 178). 108

107. Yellow ants; propodeum relatively elongate.... Monomorium laeve Mayr

Brown ants; propodeum compact and rounded ........................Monomorium fieldi Forel

108. Propodeum smooth and shining with only vestigial striae; mandible with three distinct teeth; eye rather small (approximately width of antennal scape); propodeum with declivitous face long and oblique, carinate at sides and sometimes with small lamellae at propodeal angle; anterior clypeal margin rounded; long, erect and suberect setae absent from trunk; colour tawny

.Monomorium arenarium Heterick

Propodeum shagreenate or otherwise sculptured or colour bright yellow; mandible with four teeth and denticles; clypeus usually distinctly bicarinate, clypeal carinae often produced as small denticles, if anterior clypeal margin rounded, then eye large .....109

109. Colour brown to blackish in Barrow Island populations; erect and suberect setae very rarely present on head and alitrunk; viewed in profile, promesonotum flattened and truncated (Figure 179).

Monomorium sydneyense Forel

Colour yellow or dingy yellow; erect and suberect setae often present at humeral angles; viewed in profile, promesonotum often rounded, more elongate (Figure 180) .110

110. Eye small, elliptical, eye length $\approx 1.15$ $x$ greatest width of antennal scape; six erect setae present on promesonotum and propodeum $\geq$; dingy yellow with brownishyellow gaster. Monomorium 'antipodum'

Eye larger, tending to elongate, eye length 1.75 $x$ greatest width of antennal scape $\geq$; erect mesosomal setae absent or present at humeral angles only; concolorous yellow ants ......... 111 


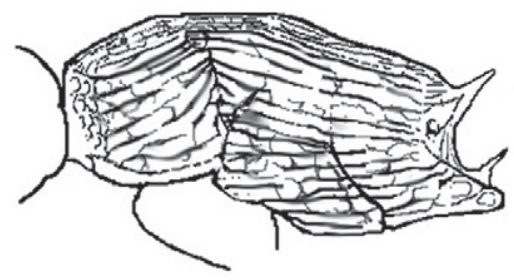

FIGURE 170

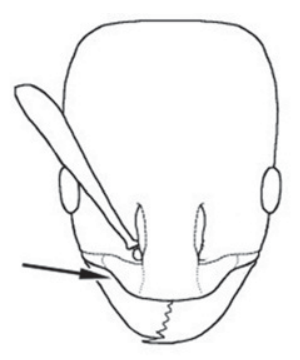

FIGURE 173

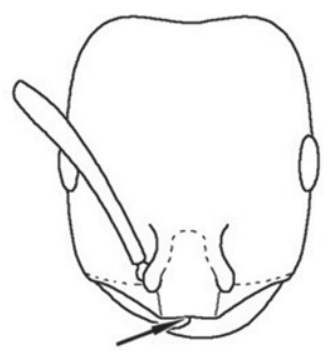

FIGURE 174

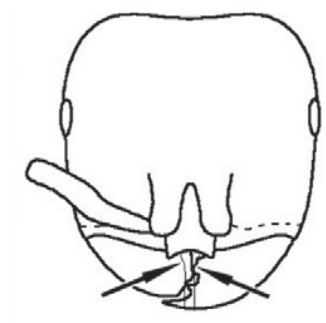

FIGURE 171

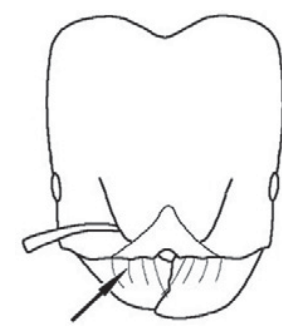

FIGURE 172

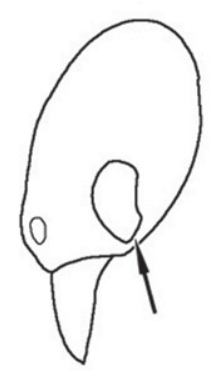

FIGURE 175

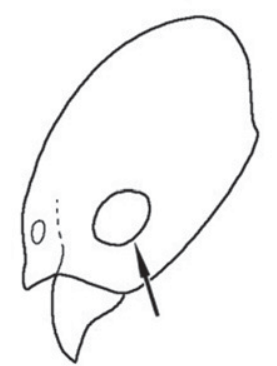

FIGURE 176

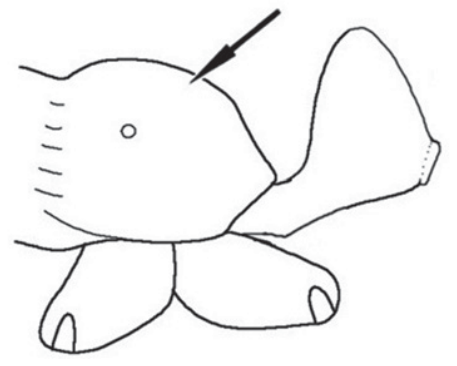

FIGURE 177

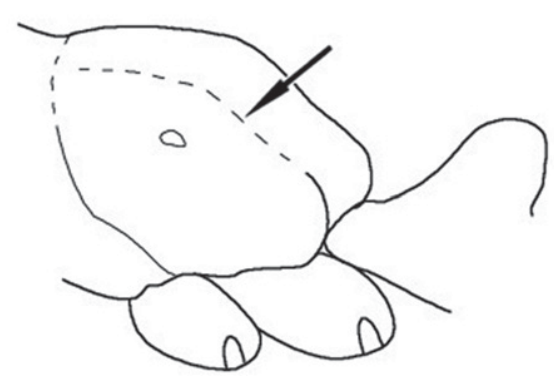

FIGURE 178

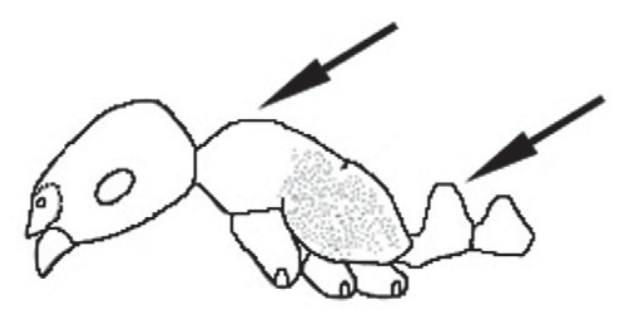

FIGURE 179

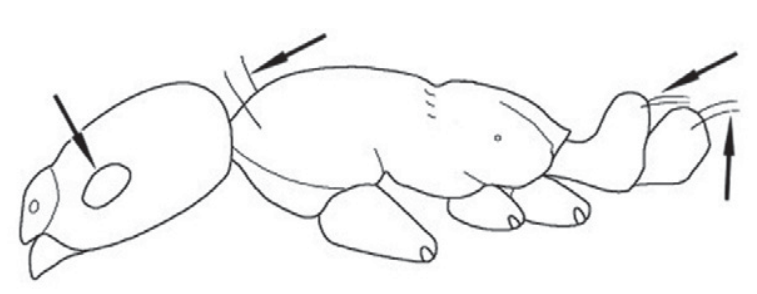

FIGURE 180 
111. Erect and suberect setae always present on body, usually presenting as a particularly prominent pair on the humeral angles and always as a pair of setae directed posteriad on the petiolar node and postpetiole, erect and suberect setae also present on gastral tergites (Figure 181); in some workers small setae that are normally appressed are subdecumbent or semierect on body and antennal scapes, giving the ant a fuzzy appearance; propodeum and katepisternum of mesopleuron usually with sculpture reduced to a few striae.

Monomorium disetigerum Heterick

Erect and suberect setae always absent from body (Figure 182); propodeum typically shagreenate and some shagreenation usually evident on mesopleuron or, at least, on katepisternum.

Monomorium sydneyense complex sp. JDM 101

112. Basal tooth much broader than other preapical teeth (Figure 183); distinctly polymorphic, with large-headed major workers having rather small eyes.... . Monomorium euryodon Heterick

Basal tooth of same size or smaller than other preapical teeth (Figure 184); worker monomorphic or exhibiting monophasic allometry .113

113. In profile, postpetiole massively developed and visibly much thicker than petiolar node; anteroventral postpetiolar process a large, conspicuously protruding lip (Figure 185) .114

In profile, postpetiole not massive, approximately as thick through as petiolar node; anteroventral postpetiolar process an inconspicuous ledge (Figure 186) .115

114. In profile, ventral surface of petiole under the node conspicuously indented just before its junction with postpetiole; petiolar node arched posteriad, its anterior face decidedly longer than its posterior face (Figure 187)........ Monomorium insolescens Wheeler
In profile, indentation of ventral surface of petiole under the node just before its junction with postpetiole barely discernible; petiolar node not obviously arched, its anterior and posterior faces approximately equal in length (Figure 188) ......Monomorium rubriceps group sp. JDM 1175

115. Head and mesosoma finely microreticulate, the ant generally weakly shining; eye large, eye length $\approx 3 \times$ greatest width of antennal scape.

Monomorium punctulatum Heterick

Head and anterior pronotum smooth and glossy with katepisternum and lower propodeal flanks reticulate and moderately shining; eye rather small, eye length $\approx 1.5 \mathrm{x}$ greatest width of antennal scape in Western Australian populations

.Monomorium leae Forel

116. Larger species (HW of minor worker $\approx$ $0.8 \mathrm{~mm}$ ); humeral angles in minor worker denoted by a small but distinct denticle (major worker unknown) (Figure 189)

Pheidole sp. JDM 684

Smaller species (HW of minor worker $\leq 0.7$ $\mathrm{mm}$ ); humeral angles unarmed (Figure 190)

117. Minor worker matt, uniformly microreticulate, and with striae and cross ribs on the head and mesosoma mostly only weakly indicated, if at all; propodeum weakly longitudinally bicarinate, the carinae separating dorsal and lateral surfaces in minor and major worker; viewed from above, occipital lobes of major workers smooth and glossy, without transverse rugae (Figure 191) .Pheidole sp. JDM 536

Head and mesosoma of minor worker variously sculptured (often with smooth, shining patches) or sculpture completely lacking, but where present, always including some distinct striae and cross ribs; lateral carina usually lacking on propodeum or incomplete and formed by one or more longitudinal striae; viewed from above occipital lobes of known major workers always with variably developed transverse rugae (Figure 192) .... .118 


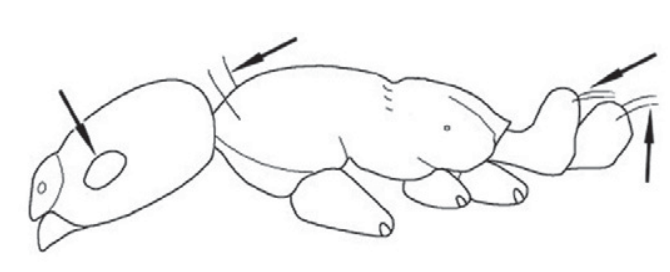

FIGURE 181

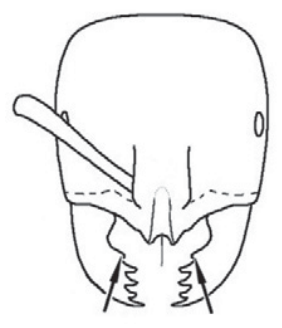

FIGURE 184

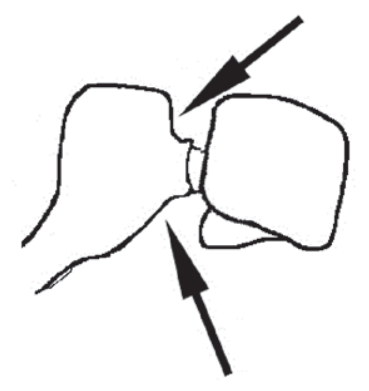

FIGURE 187

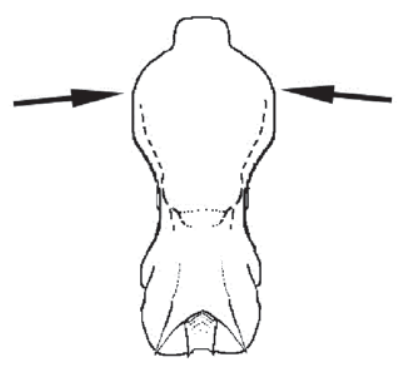

FIGURE 190

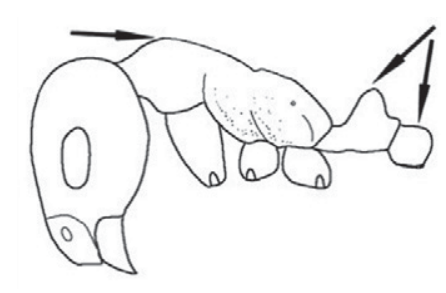

FIGURE 182

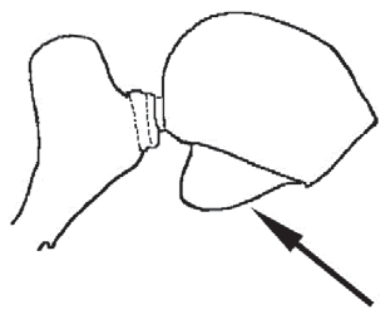

FIGURE 185

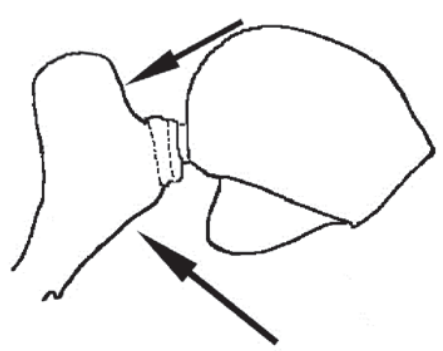

FIGURE 188

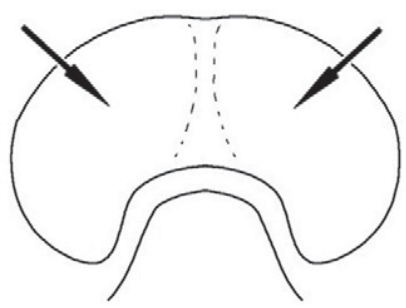

FIGURE 191

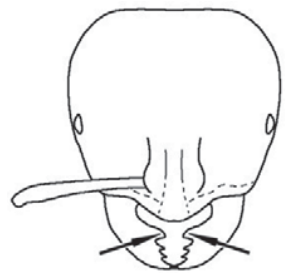

FIGURE 183

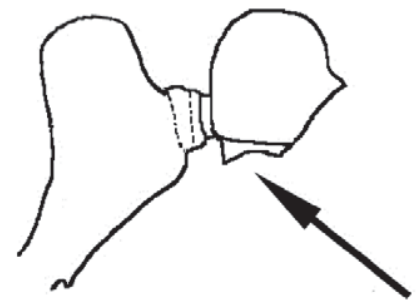

FIGURE 186

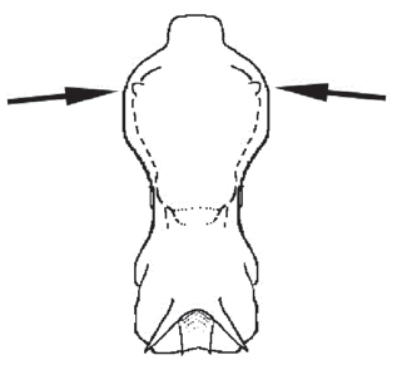

FIGURE 189

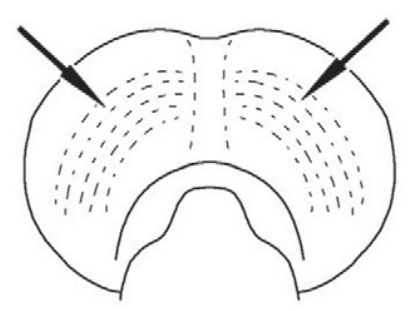

FIGURE 192 


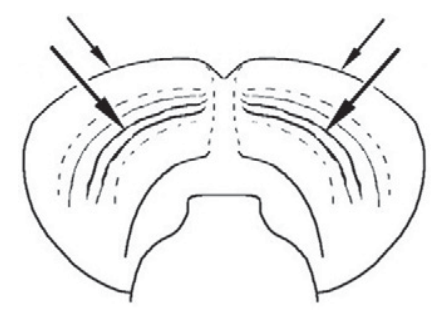

FIGURE 193

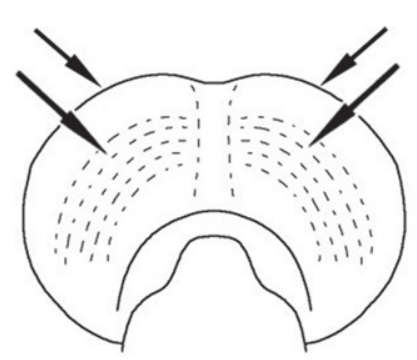

FIGURE 194
118. Minor workers yellow, the lateral humeral area of the promesonotum smooth and shining; in full-face view, frons almost smooth apart from longitudinal striae, shining; in dorsal view, occipital lobes of major worker slightly flattened, with strong transverse rugae at the apex of the lobes (Figure 193). Pheidole sp. JDM 1134

Minor workers usually shades of brown, but in paler, more tawny specimens, lateral humeral area of promesonotum almost always uniformly microreticulate; frons with microsculpture (such as microreticulation) as well as longitudinal striae, and mainly matt; in dorsal view, occipital lobes of major worker evenly rounded, the apical rugae often weaker than those lower down, or even absent (Figure 194) 119

119. Larger species (minor worker head width $\approx 0.6 \mathrm{~mm}$ ); antennal scape longer (exceeds vertex by $\geq 1 \mathrm{x}$ its greatest width) (major worker not held in JDM Collection) Pheidole mjobergi Forel

Smaller species (minor worker head width $\leq 0.5 \mathrm{~mm}$ ); antennal scape shorter (exceeds vertex by $\leq 0.5 \mathrm{x}$ its greatest width)

Pheidole sp. JDM 177 (nr variabilis Mayr)

\section{ACKNOWLEDGEMENTS}

I wish to thank Dr Nihara Gunawardene for the kind sharing of her Barrow Island Ant database, for testing the ant taxonomic key and for statistical advice. Thanks also go to Dr Christopher Taylor, who also tested the taxonomic key. The use of many Figures produced by $\mathrm{Mr}$ Brad Durrant and previously appearing in Records of the Western Australian Museum Supplement No. 76 is acknowledged. Professor Jonathan Majer commented on an initial draft. I also wish to thank the contributions of the two referees (Dr Steve Shattuck and Dr Phil Ward) who commented on the manuscript when it was submitted.

\section{REFERENCES}

Australian Broadcasting Corporation (2011). (http:// www.abc.net.au/nature/island/ep3/about1.htm). Accessed 22 February 2013. (Used with permission.)

Bureau of Meteorology (http://www.bom.gov.au/ climate/averages/tables/cw_005058.shtml). Accessed 22 February 2013.

Bamford, M.J. and Bamford, A.R. (2005). Gorgon Development on Barrow Island Technical Report Mammals and Reptiles. Technical Appendix C2 to Draft EIS/ERMP for the Proposed Gorgon Development. Chevron Australia, Perth, Australia.

Callan, S.K., Majer, J.D. and Moro, D. (2011). Documenting the terrestrial invertebrate fauna of Barrow Island. Australian Journal of Entomology 50: 323-343.

Clark, J. (1924a). Australian Formicidae. Journal of the Proceedings of the Royal Society of Western Australia 9: 72-89.

Clark, J. (1924b). Australian Formicidae. Journal of the Proceedings of the Royal Society of Western Australia 10: 75-89.

Clark, J. (1926). Australian Formicidae. Journal of the Royal Society of Western Australia 12: 43-51.

Clark, J. (1930a). Some new Australian Formicidae. Proceedings of the Royal Society of Victoria (n.s.) 42: $116-128$.

Clark, J. (1930b). The Australian ants of the genus Dolichoderus (Formicidae). Subgenus Hypoclinea Mayr. Australian Zoologist 6: 252-268.

Clark, J. (1934). Notes on Australian ants, with descriptions of new species and a new genus. Memoirs of the National Museum of Victoria 8: 5-20.

Clark, J. (1936). A revision of Australian species of Rhytidoponera Mayr (Formicidae). Memoirs of the National Museum of Victoria 9: 14-89.

Clark, J. (1938). The Sir Joseph Banks Islands. Reports of the McCoy Society for Field Investigation and Research. Part 10. Formicidae (Hymenoptera). Proceedings of the Royal Society of Victoria (n. s.) 50: 356-382.

Clark, J. (1943). A revision of the genus Promyrmecia Emery (Formicidae). Memoirs of the National Museum of Victoria 13: 83-149.

Clark, J. (1951). The Formicidae of Australia. Vol. 1. Subfamily Myrmeciinae. CSIRO, Melbourne. 230 pp. 
Colwell, R.K. (2009). EstimateS: Statistical estimation of species richness and shared species from samples. Version 8.2. User's Guide and application published at http:/ / viceroy.eeb.uconn.edu/estimates /

Crawley, W.C. (1915). Ants from north and south-west Australia (G. F. Hill, Rowland Turner) and Christmas Island, Straits Settlements. - Part II. Annals and Magazine of Natural History 8(15): 232-239.

Crawley, W.C. (1922). New ants from Australia. Annals and Magazine of Natural History 9(9): 427-448.

Eldridge, M.D.B., King, J.M., Loupis, A.K., Spencer, P.B.S., Taylor, A.C., Pope, L.C. and Hall, G.P. (1999). Unprecedented low levels of genetic variation and inbreeding in an island population of the black-footed rock wallaby. Conservation Biology 13: 531-541.

Emery, C. (1895). Descriptions de quelques fourmis nouvelles d'Australie. Annales de la Société entomologique de Beloique 39: 345-358.

Emery, C. (1898). Descrizioni di formiche nuove malesi e australiane. Note sinonimiche. Rendiconti delle Sessioni dell'Accademia delle Scienze dell'Istituto di Bologna (n.s.) 2: 231-245.

Forel, A. (1907). Formicidae. In: Michaelsen, W., Hartmeyer, R. (eds.) Die Fauna Südwest-Australiens. Band I, Lieferung 7. Gustav Fischer: Jena. pp. 263-310.

Forel, A. (1915). Results of Dr. E. Mjöbergs Swedish Scientific Expeditions to Australia 1910-13. 2. Ameisen. Arkiv för Zoologie 9 (16): 1-119.

Gunawardene, N. R. and Majer, J. D. (2004). Ants of the southern Carnarvon Basin, Western Australia: an investigation into patterns of association. Records of the Western Australian Museum 22: 219-239.

Heterick, B. E. (2001). Revision of the Australian ants of the genus Monomorium (Hymenoptera: Formicidae). Invertebrate Taxonomy 15: 353-459.

Heterick, B. E. (2003). Two new Australian Monomorium Mayr (Hymenoptera: Formicidae), including a highly distinctive species. Australian Journal of Entomology 42: 249-253.

Heterick, B. E. (2009). A guide to the ants of Southwestern Australia. Records of the Western Australian Museum, Supplement 76: 1-206.

Heterick, B. E., Durrant, B., and Gunawardene, N. R. (2010). The ant fauna of the Pilbara Bioregion, Western Australia Records of the Western Australian Museum Supplement 78: 157-167.

Heterick, B.E. and Shattuck, S.O. (2011). Revision of the ant genus Iridomyrmex. Zootaxa 2845: 1-175.

Kohout, R. J. (2013). Revision of Polyrhachis (Hagiomyrma) Wheeler 1911 (Insecta: Hymenoptera: Formicidae: Formicinae). Memoirs of the Queensland Museum/ Nature 56(2): 487-577.

McAreavey, J. (1947). New species of the genera Prolasius Forel and Melophorus Lubbock (Hymenoptera, Formicidae). Memoirs of the National Museum of Victoria 15: 7-27.

McAreavey, J. (1949). Australian Formicidae. New genera and species. Proceedings of the Linnean Society of New South Wales 74: 1-25.

McAreavey, J. (1956). A new species of the genus Meranoplus. Memoirs of the Queensland Museum 13: 148-150.
McAreavey, J. (1957). Revision of the genus Stigmacros Forel. Memoirs of the National Museum of Victoria 21: 7-64.

Ogata, K. and Taylor, R. W. (1991). Ants of the genus Myrmecia Fabricius: a preliminary review and key to the named species (Hymenoptera: Formicidae: Myrmeciinae). Journal of Natural History 2 25: 1623-1673.

Rabeling, C., Brown, J.M. and Verhaagh, M. (2008). Newly discovered sister lineage sheds light on early ant evolution. Proceedings of the National Academy of Sciences 105: 14913-14917.

Shattuck, S. O. (1993a). Revision of the Iridomyrmex purpureus species-group (Hymenoptera: Formicidae). Invertebrate Taxonomy 7: 113-149.

Shattuck, S. O. (1993b). Revision of the Iridomyrmex calvus species-group (Hymenoptera: Formicidae). Invertebrate Taxonomy 7: 1303-1325.

Shattuck, S. O. (1996a). Revision of the Iridomyrmex discors species-group (Hymenoptera: Formicidae). Australian Journal of Entomology 35: 37-42.

Shattuck, S.O. and McMillan, P. (1998). Revision of the species of the Iridomyrmex conifer group (Hymenoptera: Formicidae), with notes on their biology. Australian Journal of Zoology 46: 301-315.

Shattuck, S.O. and McArthur, A.J. (2002). A taxonomic revision of the Camponotus wiederkehri and perjurus species-groups (Hymenoptera: Formicidae). Transactions of the Royal Society of South Australia 126: 63-90.

Shattuck, S.O. (2007). New species of myrmicine ants from Western Australia. Zootaxa 1661: 47-53.

Shattuck, S.O. (2008a). Australian ants of the genus Aphaenogaster. Zootaxa 1677: 25-45.

Shattuck, S.O. (2009b). Austromorium, a new myrmicine ant genus from Australia. Zootaxa 2193: 62-68.

Shattuck, S. O., Gunawardene, N. R. and Heterick, B. (2012). A revision of the ant genus Probolomyrmex in Australia and New Guinea. Zootaxa 3426: 1-28.

Smith, F. (1858). Catalogue of hymenopterous insects in the collection of the British Museum. Part VI. Formicidae. British Museum: London. 216 pp.

Smith, F. (1877). Descriptions of new species of the genera Pseudomyrma and Tetraponera, belonging to the family Myrmicidae. Transactions of the Entomological Society of London 1877: 57-72.

Taylor, R. W. (1962a). New Australian dacetine ants of the genera Mesostruma Brown and Codiomyrmex Wheeler (Hymenoptera-Formicidae). Breviora 152: 1-10.

Taylor, R. W. (1973). Ants of the Australian genus Mesostruma Brown (Hymenoptera: Formicidae). Journal of the Australian Entomological Society 12: 24-38.

Ward, P.S. (2007a). Phylogeny, classification, and specieslevel taxonomy of ants. Zootaxa 1668: 549-563.

Wheeler, W. M. (1934). Contributions to the fauna of Rottnest Island, Western Australia. No. IX. The ants. Journal of the Royal Society of Western Australia 20: 137-163.

MANUSCRIPT RECEIVED 8 AUGUST 2012; ACCEPTED 20 MARCH 2013. 


\section{ADDENDUM}

Since this paper was compiled and submitted for review, two additional ant species have been discovered on the Island. Iridomyrmex bicknelli Emery is a gracile, iridescent species that is common in much of southern Australia, but is much rarer north of the Tropic of Capricorn. The ant will come out in the taxonomic key at couplet 65 , and can easily be distinguished from I. anceps and I. minor by its uniform dark grey colouration and bluish or yellowish-green iridescence. Melophorus sp. JDM 951 will come out at couplet 41, where it can best be separated from $M$. turneri in respect of its major caste, which is distinguished by stout, incurved mandibles that are likely used for milling seed (the mandibles not noticeably stout or incurved in $M$. turneri major workers). The minor workers of Melophorus sp. JDM 951 are matt and dark brown in colour (the cuticle normally lighter in colour and glossier in M. turneri) and the appressed setae on the gaster are relatively long and overlapping (short and well-separated in M. turneri). This species is uncommon and appears to have a localised distribution in northern Australia.

Shortly before the proofs came out, the revision of Polyrhachis (subgenus Hagiomyrma) by Kohout was published. There is some doubt about the identity of 'melanura', as the Barrow Island specimens do not quite fit the description in the published key, and occur considerably further south than the material examined by Kohout. 